\title{
Loss of Activating Transcription Factor 3 prevents KRAS-mediated pancreatic cancer
}

Nawab Azizi1,3, Jelena Toma1,3,4, Mickenzie Martin1,5, Muhammad Faran Khalid1,2, Nina Steele6, Jiaqi Shi6, Marina Pasca di Magliano7, and Christopher L. Pin1-4

12 University of Western Ontario, London, Ontario, N6A 3K7, Canada; 6Dept. of Pathology, 7 Dept.

15 Corresponding Author: Dr. Christopher Pin (to whom reprint requests should be addressed),

16 Dept. of Paediatrics, University of Western Ontario, Children's Health Research Institute, 5th

17 Floor, Victoria Research Laboratories, London, Ontario, Canada, N6C 2V5, (519) 685-8500, ext.

18 53073, FAX (519) 685-8186, e-mail: cpin@uwo.ca.

19 Key words: Unfolded Protein Response, ER stress response, pancreatic ductal adenocarcinoma,

20 acinar to ductal metaplasia

21

22 Conflict of Interest Statement: The authors have declared that no conflict of interest exists. 


\section{Abstract}

The unfolded protein response (UPR) is activated in pancreatic pathologies and suggested

3 as a target for therapeutic intervention. In this study, we examined Activating Transcription

4 Factor 3 (ATF3), a mediator of the UPR which promotes acinar-to-ductal metaplasia (ADM) in

5 response to pancreatic injury. Since ADM is an initial step in the progression to pancreatic ductal

6 adenocarcinoma (PDAC), we hypothesized ATF3 is required for initiation and progression of

7 PDAC. We generated mice carrying a germ line mutation of Atf3 (Atf3-/) combined with acinar-

8 specific induction of oncogenic KRAS (PtflacreERT/+KraSLSL-G12D). Atf3-/ mice with (termed APK)

9 and without KRASG12D were exposed to cerulein-induced pancreatitis. In response to recurrent

10 pancreatitis, Atf3-/ mice showed decreased ADM and enhanced regeneration based on

11 morphological and biochemical analysis. Similarly, an absence of ATF3 reduced spontaneous

12 pancreatic intraepithelial neoplasia formation and PDAC in PtflacreERT/+KrasLSL-G12D mice. In

13 response to injury, $\mathrm{KRAS}_{\mathrm{G} 12 \mathrm{D}}$ bipassed the requirement for ATF3 with a dramatic loss in acinar

14 tissue and PanIN formation observed regardless of ATF3 status. However, unlike

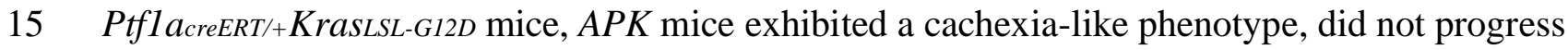

16 through to PDAC, and showed altered pancreatic fibrosis and immune cell infiltration. These

17 findings suggest a complex, multifaceted role for ATF3 in pancreatic cancer pathology. 


\section{Introduction}

The unfolded protein response (UPR) is a critical pathway protecting cells from a variety

3 of harmful stresses that promote improper protein folding or processing $[1,2]$. In response to

4 accumulation of misfolded proteins, the UPR is activated to reduce protein load through a

5 general decrease in protein translation, activation of ER-associated degradation, and increased

6 expression of protein chaperones [1-3]. Over the last decade, the UPR has been implicated in a

7 variety of human pathologies, including breast [4], lung [5] and colorectal cancer [6, 7]. In the

8 pancreas, the UPR plays important roles in both physiological and pathological processes. More

9 recently, the UPR has been suggested as a mediator and potential therapeutic target for

10 pancreatic ductal adenocarcinoma (PDAC; $[8,9]$. PDAC is currently the third leading cause of

11 cancer-related deaths, with a dismal 5-year survival rate of $\sim 9 \%$. While constitutive activation of

12 KRAS is an initiating event in PDAC, targeting this pathway has been futile to date, suggesting

13 alternative targets need to be identified. Studies with pancreatic cancer cell lines indicate that

14 targeting the UPR may be beneficial $[8,10]$. However, the mechanism(s) of action of the UPR in

15 cancer initiation and progression have been elusive. This is likely due to the numerous levels of

16 regulation that exist for the UPR both before and after activation.

17 Within acinar cells, the UPR plays a pivotal role in normal physiology, preventing

18 accumulation of misfolded proteins in the ER lumen and maintaining protein homeostasis [11].

19 The UPR consists of three signalling branches - PERK ([PKR]-like ER kinase), IRE1 (inositol

20 requiring enzyme 1) and activating transcription factor 6 (ATF6; [12]. These ER-membrane

21 associated proteins are triggered through dissociation of GRP78/BiP in response to accumulation

22 of misfolded protein [13]. Activation of PERK leads to phosphorylation of eIF2 $\alpha$ which then

23 leads to global inhibition of mRNA translation [14]. An important mediator of PERK signaling is 
1 ATF4, which is transcribed but in the absence of stress, but not translated as a functional protein

2 [15]. Upon stress, Atf4 avoids translational inhibition, is translated from an alternative promoter,

3 and activates genes that regulate protein folding, degradation and cell survival [16, 17]. PERK

4 signaling also activates $\operatorname{Atf} 3$ gene expression [18].

Likely due to the high protein turnover rate in acinar cells [19], deletion of genes encoding several important mediators of the UPR, including PERK [20], IRE1 [19] and ATF4 [20], all result in pancreatic pathology highlighting their importance to acinar cell physiology. To understand the pathological requirement of the UPR, we have focused on ATF3, which is not expressed in the pancreas until induced by injury, such as observed in pancreatitis [21]. Previous work from our laboratory and others showed ATF3 expression is rapidly induced in acinar cells

11 by experimental forms of pancreatitis $[22,23]$. In other organs or pathologies, ATF3 affects

12 signaling pathways and cellular processes that are observed in pancreatitis and PDAC. ATF3

13 interacts with SMAD and MAPK signaling pathways [24] to relieve stress through DNA damage

14 repair and cell cycle regulation [25], binds NF- $\mathrm{BB}$ and represses the expression of cytokines such

15 as IL-6 and TLR-4 [26, 27], and is vital for neutrophil migration to areas of injury in lung tissue

16 [28]. In the skin, ATF3 is critical for negatively regulating cancer-associated fibroblasts (CAFs)

17 to prevent the excessive deposition of extracellular matrix (ECM) proteins that would otherwise

18 promote carcinogenesis [29].

While roles for ATF3 has been identified in several cancers, these are cell and cancer-

20 type dependent $[6,7,30]$. Conflicting roles for ATF3 have been reported for metastatic prostate

21 cancer [31]. In breast cancer, high levels of ATF3 is associated with reduced patient survival and

22 promotes tumour development and metastasis [32]. Alternatively, in colon and colorectal

23 cancers, ATF3 overexpression reduces cell survival by exerting anti-tumorigenic effects [33, 34]. 
1 ATF3's role in pancreatic cancer has not been examined to date.

2 Loss of the acinar cell phenotype or ADM (acinar to ductal metaplasia) is an early event

3 in chronic pancreatitis and PDAC. Our laboratory showed ATF3 is required for ADM during

4 acute injury [22] by activating Sox9 (Sry-related high-mobility group box 9) and repressing

5 Mist1, which maintains the mature acinar cell phenotype [35]. SOX9 and MIST1 are important

6 regulators of ADM, required for [36] or limiting [37] PDAC progression through

7 ADM/pancreatic intraepithelial neoplasia (PanIN) formation, respectively.

8 These studies suggest ATF3 may have an early role in progression of PDAC, possibly

9 through regulation of key transcription factors involved in the ADM process. However, while

10 recurrent or chronic forms of pancreatitis are a significant risk factor for PDAC, acute

11 pancreatitis is a poor predictor of PDAC [38]. Therefore, in this study we investigated whether

12 ATF3 is required for ADM in recurrent injury and whether oncogenic KRAS could override this

13 requirement. Our findings suggest ADM can occur in KRAS-mediated PDAC, but ATF3 is

14 required for progression and maintenance of high grade PanIN lesions and PDAC. In addition, it

15 appears that ATF3 may affect multiple cell types involved in PDAC.

16

17 


\section{Results}

2 ATF3 is required for activating the transcriptional program for ADM during recurrent

3 pancreatic injury

$4 \quad$ To determine if ATF3 is critical for the loss of the acinar cell phenotype during recurrent

5 pancreatic injury, congenic wild type and Atf3-/-mice were subjected to rCIP for 14 days

6 (Supplemental Figure S1A). Pancreatic tissue was collected one and seven days following

7 cessation of cerulein to assess the extent of injury and regeneration, respectively. No gross

8 morphological differences were observed between WT and Atf3-^ mice during rCIP. Both

9 cerulein-treated groups showed significant weight loss compared to saline treated groups

10 (Supplemental Figure S1B), but the difference minimized after cerulein was stopped. One day

11 following treatment, both cerulein-treated groups showed a significant decrease in pancreas/body

12 weight ratio relative to saline groups (Figure 1A), with no difference between WT and Atf3--

13 mice. Both genotypes acquired a similar extent of damage (Figure 1B), including loss of acinar

14 tissue based on amylase IHC (Figure 1C) and western blot analysis (Figure 1D) and fibrosis

15 (Supplemental Figure S2). While morphological staining indicated similar accumulation of duct-

16 like structures in cerulein-treated WT and Atf3-/ tissue (Figure 2A), IHC for CK19 expression

17 was less extensive in Atf3-^tissue (Figure 2B). Quantification of the extent of CK19

18 accumulation confirmed a reduction in the total amount of CK19+ cells in Atf3-/ tissue compared

19 to WT mice (Figure 2C).

Seven days after rCIP, the differences between WT and Atf3-/ pancreatic tissue were

21 striking. Pancreas to body weight ratio of cerulein-treated Atf3-/ mice was similar to saline-

22 treated mice while cerulein-treated WT mice still had significantly smaller pancreata relative to

23 all other groups (Figure 1A). Histological analysis showed almost a complete recovery of acinar 
1 tissue in cerulein-treated Atf3-/ mice while WT mice retained areas of damage (Figure 1B).

2 Acinar tissue was restored more quickly based on histology (Figures 1B, 2A, S2A), amylase

3 accumulation (Figures 1C-E) and CK19 accumulation (Figure 2B, C). Analysis of fibrosis

4 showed no difference between WT and Atf3-љ mice, with overall fibrosis reduced by day seven

5 compared to day one in both genotypes (Supplemental Figure S2).

Our previous work indicated ATF3 directly regulated expression of transcription factors involved in ADM [22]. IF for SOX9, which is required for ADM [36, 39], showed limited

8 expression in saline-treated animals, localizing specifically to ductal epithelial cells. As

9 previously reported, SOX9 expression was observed in acinar cells and ADM structures 1 and 7

10 days following rCIP in WT mice (Figure 3A, B). This finding was confirmed by Western

11 blotting (Supplemental Figure S3A). Conversely, SOX9 expression was observed only

12 sporadically in cerulein-treated Atf3-/ tissue (Figure 3A, B) with no increase observed by

13 Western blot analysis (Supplemental Figure S3A). Similar analysis for PDX1 showed increased

14 accumulation in ADM structures in cerulein-treated WT pancreas tissue, while PDX1 expression

15 was greatly reduced in both intensity (Supplemental Figure S3B) and frequency in cerulein-

16 treated Atf3-/ pancreas tissue (Supplemental Figure S3C).

We next examined MIST1, which is required for establishing the mature acinar cell

18 phenotype [40]. As previously reported [22], MIST1 expression is significantly reduced in WT

19 acinar cells one day following cessation of cerulein treatment (Figure 3C, D). Seven days after

20 treatment, MIST1 expression returned to control levels. Conversely, this temporal decrease in

21 MIST1 expression was not observed in cerulein-treated Atf3-/ tissue (Figure 3C, D). Combined,

22 this data suggests that Atf3-/ mice recover more quickly from rCIP, possibly through limiting

23 activation of a more progenitor-like state in response to injury. 
1 Absence of ATF3 reduces spontaneous PanIN progression following KRASG12D activation

While ATF3 was required for activating the ADM transcriptional program in response to

3 injury, it is possible that oncogenic KRAS can bypass this requirement. Therefore, Atf3-/- mice

4 were mated to mice allowing inducible activation of oncogenic KRAS (KRASG12D).

5 Recombination was limited to acinar cells by targeting a creERT to the Ptfla gene [41]. These

6 mice contained a $R O S A 26$ reporter gene $(R 26 r-Y F P)$ allowing analysis of cre-mediated

7 recombination. Two to four-month old mice with (Atf3+/+ or Atf3+/-PtflacreERT/+KrasLSL-G12D/+;

8 referred to as PtflacreERT/+KrasG12D/+) or without ATF3 (Atf3-/PtflacreERT/+KrasLSL-G12D/+; referred

9 to as $A P K)$ were treated with tamoxifen for five days (Supplemental Figure S4A). This resulted

10 in $>97 \%$ acinar-specific recombination in both mouse lines with no observable recombination in

11 duct or islet tissue based on activation of the ROSA26r-LSL-YFP locus (Supplemental Figure

12 S4B). One cohort of mice was followed for 13 weeks to determine if spontaneous ADM and

13 PanIN lesions were affected by the absence of ATF3 (Supplemental Figure S4A). All groups

14 showed a decrease in weight in response to tamoxifen, which was regained over the course of the

15 experiment (Supplemental Figure S4C, D). Upon dissection, 2/5 PtflacreERT/+KrasG12D/+ mice

16 contained pancreata with some fibrotic masses observed at the gross morphological level (data

17 not shown). Pancreatic weight as a percentage of total body weight was increased in

$18 P t f l a_{c r e E R T /+K r a S G 12 D /+}$ mice relative to all other genotypes (Figure 4A). H\&E analysis confirmed

19 significant disruptions to pancreatic architecture, including loss of acini, extensive PanIN lesions,

20 inflammation, and fibrosis in 2/5 PtflacreERT/+KrasG12D/+ mice (Figure 4B). In the remaining three

$21 P t f l a_{c r e E R T /+K r a s G 12 D /+}$ mice, areas of ADM and early PanIN lesions were readily observed

22 (Figure 4C). IF revealed SOX9 expression within the ADM and PanIN lesions observed in

23 PtflacreERT/+KrasG12D/+ tissue (Figure 4D). Conversely, APK mice showed only sporadic 
1 ADM/PanIN lesions (Figure 4B) with minimal SOX9 expression (Figure 4D) and no PanIN2 or

2 PanIN3 lesions. These results indicated ATF3 was required for spontaneous KRASG12D-mediated

3 PanIN formation.

4

Oncogenic KRAS bypasses the requirement of ATF3 for ADM following injury

Next, we exposed PtflacreERT/+KrasG12D/+ and APK mice to a two-day regime of acute cerulein treatment seven days after tamoxifen treatment and examined pancreatic tissue two and

8 five weeks after cerulein treatment (Supplemental Figure S4A). During tamoxifen treatment and

9 acute CIP, mice were weighed daily. All saline-treated mice, regardless of ATF3 expression or

10 oncogenic KRAS activity gained body weight over the experimental time period (Supplemental

11 Figure S5A). CIP-treated PtflacreERT/+KrasG12D/+ mice showed reduced body weight starting 43

12 days after tamoxifen treatment compared to PtflacreERT/+ and Atf3-/PtflaCreERT/+ mice, while APK

13 mice treated with cerulein had significantly reduced body weight compared to all other

14 genotypes 31 days into treatment (Supplemental Figure S5B). Both PtflacreERT/+KrasG12D/+ (3/22)

15 and $A P K$ lines (1/14) exhibited some mortality during the 5-week experimental time point. Upon

16 dissection, APK mice appeared much smaller than other groups with negligible abdominal wall

17 muscle observed in most of these mice (data not shown). APK mice also had significantly smaller

18 pancreata at both time points examined relative to other genotypes (Supplementary Figure S5C,

19 D). Conversely, cerulein-treated PtflacreERT/+KrasG12D/+ mice had significantly increased

20 pancreatic weight relative to body weight (Supplementary Figure S5D) compared to all other

21 groups two weeks post treatment, with multiple fibrotic nodules visible (Supplementary Figure

22 S5C). By five weeks, the difference in pancreatic/body weight was no longer apparent in

$23 P t f l a_{c r e E R T /+K r a s G 12 D /+}$ mice, even though nodules were still present. Histological analysis of 
1 pancreatic tissue indicated widespread loss of acinar tissue and development of PanIN lesions

2 within two weeks of inducing CIP in $A P K$ and PtflacreERT/+KrasG12D/+ pancreatic tissues (Figure

3 5A). The loss of acinar tissue was confirmed by a complete absence of amylase accumulation

4 based on western blot analysis (Figure 6A, B).

6 progression. Saline and cerulein-treated control Ptfl $a_{c r e E R T /+}$ and Atf3-/PtflacreERT/+ tissue showed

7 no damage either two or five weeks after treatment (Supplemental Figure 6A; Figure 5A). To

8 determine if the pathological phenotype was the same between $A P K$ and PtflacreERT/+KrasG12D/+

9 mice, tissue was assessed based on the highest grade lesion present per tissue area (Table 1). As

10 suggested from 13-week analysis, saline-treated APK and PtflacreERT/+KrasG12D/+ mice showed

11 some pre-neoplastic lesions (Supplemental Figure S6A, B; Table 1). Upon CIP-treatment, $A P K$

12 and PtflacreERT/+KrasG12D/+ mice treated with cerulein showed high grade PanIN3 lesions two

13 weeks after CIP (Figure 5A; Table 1). However, by week five, $A P K$ tissue showed

14 predominately low grade PanIN1 and 2 lesions compared to predominantly high grade PanIN3

15 and PDAC lesions observed in Ptfla $a_{c r e E R T /+K r a s G 12 D /+}$ tissue (Table 1). The decrease in

16 progressive PanIN lesions in $A P K$ mice was also reflected by significantly lower accumulation of

17 CK19+ ducts in APK tissue compared to PtflacreERT/+KrasG12D/+ mice (Supplementary Figure

18 S6B, C). Alcian blue stain, which identifies mucin and suggests metaplastic PanIN lesions, was

19 significantly reduced in $A P K$ tissue relative to PtflacreERT/+KrasG12D/+ tissue (Figure 5C, D).

20 Finally, epithelial cell proliferation in PanINs was examined by Ki-67 fluorescence. Ki67+ cells

21 were reduced at two weeks and completely absent at five weeks in APK lesions relative to

22 PtflacreERT/+KrasG12D/+ tissue (Figure 5E, F). Therefore, while overall histology was similar

23 between $A P K$ and PtflacreERT/+KrasG12D/+ tissue, multiple analyses suggest the absence of ATF3 
1 affects KRASG12D-mediated progression to PDAC.

We next examined if the molecular profile for ADM progression was present in $A P K$

3 mice. Both transcriptional (SOX9) and signaling mediators (phosphorylated MAPK1/2) of ADM

4 (Figure 6) were examined. IF for SOX9 showed equivalent numbers of SOX9+ cells two weeks

5 after CIP in PtflacreERT/+KrasG12D/+ and APK tissue (Figure 6D), but with significantly lower

6 SOX9 accumulation in $A P K$ tissue based on western blot analysis (Figure 6A, C; SOX9

7 accumulation is $7.99 \pm 1.24$-fold higher in PtflacreERT/+KrasLSL-G12D/+ extracts compared to APK).

8 By five weeks post-cerulein, both the number (Figure 6D) and level of SOX9 accumulation was

9 reduced in APK mice (Figure 6C; $2.58 \pm 1.41$-fold higher in PtflacreERT/+KrasLSL-G12D/+ extracts).

10 The decreased expression of the ADM-promoting SOX9 was consistent with decreased

11 activation of MAPK signalling in APK tissue based on western blot analysis for pERK both two

12 (2.21 \pm 0.66 -fold less pERK) and five weeks (2.42 \pm 0.25 -fold less pERK) after injury compared

13 to Ptfla $a_{c r e E R T /+K r a s G 12 D /+}$ tissue (Figure 6A, E). Combined, these results suggest that the absence

14 of ATF3 in the presence of KRASG12D reduces the activation of factors promoting ADM and

15 PanIN formation. Therefore, while the requirement of ATF3 for ADM can be bypassed by

16 KRASG12D, ATF3 appears to be required for maintaining high-grade PanIN lesions.

18 An absence of ATF3 affects the fibrotic and inflammatory pathways affected by oncogenic KRAS

Previous analysis of ATF3 in other cancers suggests an important role in fibrosis and

20 inflammatory processes. To determine if the global absence of ATF3 affects these two elements

21 in PDAC progression, we compared expression of markers for stellate cells and inflammation

22 between $A P K$ and PtflacreERT/+KrasG12D/+ mice. Fibrosis, as determined by Mason's Trichrome

23 stain, was significantly higher two weeks post injury in $A P K$ tissue compared to 


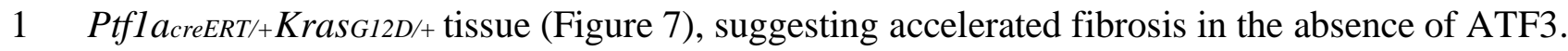

2 By five weeks, no difference was observed in fibrosis between these two genotypes (Figure 7) as

3 the level of fibrosis appears to lessen in $A P K$ mice. Interestingly, analysis of $\alpha$-smooth muscle

4 actin ( $\alpha$-SMA), a marker of activated fibroblast cells, showed no difference in accumulation

5 based on western blot analysis (Supplementary Figure 7).

Next, to compare the immune cell infiltrate between APK and PtflacreERT/+KrasG12D/+

7 mice, we performed mass cytometry (CyTOF) on pancreatic tissue from mice two weeks after

8 cerulein treatment. CyTOF experiments revealed a decreased infiltration of macrophages in $A P K$

9 mice with a concomitant increase in T lymphocyte accumulation (Figure 8A, B). To confirm

10 these findings, we performed IF for F4/80, a macrophage-specific marker (Figure 8C). In

11 confirmation of the CyTOF experiments, significantly fewer macrophages were observed in $A P K$

12 tissue compared to PtflacreERT/+KrasLSL-G12D/+ tissue five weeks after injury (Figure 8D). These

13 results suggest the global loss of ATF3 has both acinar and non-acinar specific role in affecting

14 KRASG12D-mediated PDAC progression. 


\section{Discussion}

In this study, we identified a novel role for ATF3 in recurrent pancreatic injury and

3 progression to PDAC. Recurrent pancreatitis is a significant risk factor for PDAC, possibly due

4 to the combined effects of inflammation and loss of the acinar cell phenotype through ADM.

5 Through examining the effects of Atf3 deletion on the acinar cell response to recurrent injury or

6 constitutive KRAS activation, we identified a complex role for ATF3 in affecting multiple cell

7 types within the pancreas. The absence of ATF3 prevented full activation of the ADM

8 transcriptional profile and limited spontaneous PanIN formation in the presence of oncogenic

9 KRAS. This requirement for ATF3 in ADM and PanIN progression appears dispensable when

10 constitutive KRAS activation is combined with injury. However, the maintenance of high grade

11 PanINs and progression to PDAC still required ATF3. In addition, we observed a transient

12 increase in fibrosis and an altered inflammatory response with a decreased macrophage

13 infiltration. These results suggest that, in addition to ADM, ATF3 also affects stellate cells and

14 myeloid cells. Whether this is through cell autonomous pathways or mediated by epithelial cell

15 interactions needs to be investigated in future studies.

16 Previous work from our lab identified a requirement for ATF3 in activating ADM

17 transcriptional profile during acute injury. We have now assessed ATF3's role in conditions that

18 promote PDAC. As observed in acute injury, ATF3 is required for changing the expression of

19 key transcriptional regulators of the ADM process, including PDX1, SOX9 and MIST1.

20 Increased expression of SOX9 and PDX1 observed during injury [42] is required for maintaining

21 ADM morphology and expression of duct-specific genes such as $C k 19$ [43]. Conversely, MIST1

22 expression is rapidly decreased. In the absence of ATF3, SOX9 and PDX1 expression are

23 reduced compared to WT mice, while MIST1 expression was not completely repressed. The 
1 incomplete activation of the ADM transcriptome likely accounted for the more rapid

2 regeneration exhibited by Atf3 «- mice following rCIP. Interestingly, structures resembling ADM

3 were still observed and amylase accumulation was almost completely lost even while some

$4 \quad$ MIST1 expression persisted. Therefore, recurrent injury still promoted the loss of mature acinar

5 cell phenotype in the absence of ATF3, even without activation of SOX9. Similar observations

6 of partial ADM have been observed in Sox9-deficient acinar cells [44], likely through

7 compensatory mechanisms involving Hepatocyte nuclear factor 6 (HNF6; [45]. HNF6 works

8 synergistically with SOX9 to promote ADM development.

$9 \quad$ Based on the rapid regeneration and reduced ADM exhibited by Atf3 - mice, as well as

10 the finding that $A P K$ mice do not develop PDAC, it is tempting to suggest ATF3 may be a target

11 for inhibiting KRAS-mediated PDAC. In fact, we observed little to no transformation of acinar

12 cells following activation of KRASG12D in mature $A P K$ acinar cells. Conversely, high grade

13 PanINs were readily observed in a subset of PtflacreERT/+KrasLSL-G12D/+ mice 13 weeks after

14 KRAS $_{\mathrm{G} 12 \mathrm{D}}$ activation. However, our findings suggest the absence of ATF3 is detrimental to

15 regeneration when oncogenic KRAS is expressed in addition to injury. Following induction of

16 pancreatitis, acinar cells expressing KRASG12D appear to bypass the requirement of ATF3. SOX9

17 expression increases and high grade PanIN lesions are observed in $A P K$ mice two weeks

18 following injury. However, SOX9 accumulation was reduced in APK mice two weeks following

19 injury and almost completely absent by five weeks suggesting an altered molecular profile for

$20 \mathrm{ADM}$ and PanINs in the absence of ATF3. Unlike SOX9, the expression of Hnf6 is not

21 maintained in more progressive lesions (PanIN lesions; [45], which may explain the inability of

$22 A P K$ tissue to progress to PDAC. These findings support histological findings that indicate a

23 reduction in high-grade lesions in $A P K$ tissue. 
While these findings support ATF3 requirement for persistent ADM, unlike in rCIP, the pancreata in $A P K$ mice did not regenerate. $A P K$ pancreata were significantly smaller in size than

3 all other genotypes and histological analysis revealed increased fibrosis in $A P K$ tissue at two

4 weeks, suggesting Atf3's deletion affects stellate cell function. Whether the fibrosis observed in

$5 A P K$ tissue limits pancreatic regeneration in these mice is unclear, but the amount and type of

6 fibrosis can affect progression to PDAC. There is also a loss of fibrosis between two and five

7 weeks in $A P K$ mice. While it is likely that this results from a general wasting within $A P K$ mice,

8 we cannot rule out the possibility that factors are promoting resorption of the ECM. Therefore,

9 future work will assess the ECM to determine if stellate cells in APK mice have a different

10 expression profile. We also observed a cachexia-like phenotype in $A P K$ mice, which lost on

11 average $15 \%$ of their starting body weight within five weeks. Cachexia results in part from an

12 altered metabolic phenotype, leading to significant loss of muscle. While ATF3 has not yet been

13 implicated in metabolism, the related protein ATF4 does regulate amino acid metabolism in

14 CD4+ T cells. Our previous work showed ATF3 targeted many genes also regulated by ATF4

15 and Gene Ontology analysis identified dysregulation of several pathways involved in amino acid

16 metabolism in Atf3-/ mice in response to acute pancreatic injury [22]. In support of a role for

17 ATF3 in the inflammatory response during PDAC, we observe decreased myeloid cell

18 infiltration combined with a trend in increased CD4+ T cells. Whether the gene

19 expression/function of these cells is altered needs to be assessed.

21 use these mice as they show no phenotype without the induction of some form of stress.

22 However, we cannot determine whether the phenotypes are the result of acinar or non-acinar

23 requirements for ATF3 gene regulation. We previously showed ATF3 enrichment at $\sim 35 \%$ of the 
1 genes altered four hours into cerulein-induced pancreatic injury including genes involved in

2 affecting metabolism, promoting inflammation and ECM production. Therefore, it is possible

3 that ATF3 regulates stellate and inflammatory cells indirectly through cross-talk with acinar

4 cells. Lineage tracing analysis confirmed recombination, and therefore KRASG12D expression,

5 was limited to acinar cells and PanIN lesions derived from acinar cells. Therefore, we are not

6 observing the results of activating KRAS in non-acinar cells. It is known that ATF3 can affect

7 cancer progression in other systems through non-cell autonomous regulation [46-48]. However,

8 these studies identified a non-cell autonomous for non-tumour cells expressing ATF3. Published

9 data identified ATF3 expression in both inflammatory and ECM-producing cells in other

10 pathologies including breast and lung cancer [29, 49] and our findings indicate ATF3 is

11 expressed in these cell populations in the context of PDAC. Therefore, it is likely that ATF3

12 directly affects the function of both stellate and myeloid cells in the context of PDAC. Indeed, it

13 is possible that the transient increase in fibrosis and inability to maintain high grade lesions in

$14 A P K$ mice may be due to the difference in inflammatory response. Tumor-associated

15 macrophages promote cancer fibrosis by secreting factors that activate fibroblast-mediated

16 extracellular matrix remodeling [50].

17 In summary, the findings in this study support several roles for ATF3 in pancreatic injury

18 and PDAC related to acinar, stellate and immune cells. Future work to tease out cell-specific

19 roles for ATF3 will need to involve cell-specific deletion of Atf3 in the context of oncogenic

20 KRAS. In addition, the potential for targeting the UPR, and ATF3 specifically, in the context of

21 pancreatic pathologies will need to account for this multifaceted role. 


\section{$1 \quad$ Materials and Methods}

\section{Mouse Models}

Two-to-four month old male and female C57/B16 mice or congenic mice carrying a germline deletion of Atf3 (Atf3-/; [51]) were used for recurrent cerulein-induced pancreatitis (rCIP) studies. Alternatively, Atf3-/ mice were bred to mice in which a tamoxifen-inducible cre recombinase (creERT) was targeted to the Ptfla allele (PtflacreERT/+; [41]. Atf3-_PtflacreERT/+ mice were crossed to mice carrying a constitutively active Kras gene (KRASG12D) preceded by loxP sites flanking a stop codon (loxP-stop-loxP; LSL) and targeted to the Kras allele (KrasLSL-G12D/+; [52]. Through subsequent mating on a C57/B16 background, we generated Atf3+/+PtflacreERT/+KrasLSL-G12D/+ (referred to as PtflacreERT/+KrasLSL-G12D/+) and Atf3-/-

PtflacreERT/+KrasLSL-G12D/+ mice (referred to as APK). In some cases, mice heterozygous for Atf3 (Atf3+/-) were included in the PtflacreERT/+KrasLSL-G12D/+ cohort as loss of a single copy of Atf3 has no documented effects REF. To allow lineage tracing of acinar cells, PtflacreERT/+KrasLSLG12D/+ and $A P K$ mice were mated to mice containing a yellow fluorescent protein $(Y F P)$ gene downstream of a $L S L$ cassette targeted to the Rosa26r (Rosa26rLSL-YFP/+) allele. Genotypes were confirmed before and after experimentation using the primers indicated in Supplementary Table S1.

\section{Cerulein-induced pancreatitis}

Mice were given normal chow and water ad libitum throughout the experiment. To induce recurrent pancreatic injury, Atf3-/- and Atf3+/+ mice received intraperitoneal injections of cerulein $(250 \mu \mathrm{g} / \mathrm{kg}$ body weight; Sigma; Cat. \#17650-98-5; St. Louis, MO) or 0.9\% saline (control) twice daily (9 $00 \mathrm{~h}$ and $1500 \mathrm{~h}$ ) for 14 days (Supplemental Figure S1). Mice were 
1 weighed daily to determine changes in body weight. Mice were killed one or seven days after the

2 last cerulein injections. Pancreatic weight (g) was determined post mortem and compared to total

3 body weight.

$4 \quad$ For experiments involving KRASG12D, Atf3+/+PtflacreERT/+ (designated wild type; WT);

5 Atf3-_-PtflacreERT/+, PtflacreERT/+KraSLSL-G12D/+ and APK mice received $5 \mathrm{mg}$ of tamoxifen (Sigma-

6 Aldrich; Cat. \#10540-29-1) each day for 5 days via oral gavage, producing cre-recombination

7 efficiency $>95 \%$ [41]. Seven days following tamoxifen treatment, cerulein $(50 \mu \mathrm{g} / \mathrm{kg}) \mathrm{was}$

8 administered via IP injection; 8 times over 7 hours (n values are indicated in each figure). Mice

9 were weighed daily to monitor overall health and sacrificed if their body weight was $15 \%$ lower

10 than their starting weight. Mice were killed two or five weeks after cerulein administration and

11 pancreatic tissue collected and weighed.

\section{Tissue Fixation \& Histology}

14 For histological analysis, pancreatic tissue was isolated from the head and tail of the

15 pancreas and processed as described [22]. To assess overall histology and identify differences in

16 pancreatic tissue architecture, sections were stained with H\&E. To assess fibrosis, paraffin

17 sections were stained using Mason's Trichrome stain (ab150686; Abcam Inc.) and fibrosis

18 quantified using ImageJ as a percent of total tissue area. Mucin accumulation was visualized

19 using an Alcian Blue stain kit (ab150662; Abcam Inc.) and staining quantified as a percentage of

20 the whole tissue area.

21 Tissue sections were scored for ADM, PanINs and PDAC by a pathologist blinded to

22 genotype. Progressive lesions (PanINs) were graded based on nuclear irregularities, mucinous

23 epithelium, and dense areas of fibrosis and inflammation surrounding PanIN lesions. In all cases, 
$1 \quad 10-15$ images were taken for each sample and from multiple sections at least $200 \mu \mathrm{m}$ apart using

2 an Aperio CS2 Digital Scanner and Aperio ImageScope software (Leica Biosystems Imaging

3 Inc, San Diego, CA, USA) and Leica Microscope DM5500B (Leica Microsystems, Wetzlar,

4 Germany) with LAS V4.4 software.

To assess recombination efficiency through YFP detection, tissue was fixed in $4 \%$ methanol-free paraformaldehyde for 2 hours and incubated at $4^{\circ} \mathrm{C}$. Post-fixation, samples were

7 incubated in $30 \%$ sucrose overnight at $4^{\circ} \mathrm{C}$, embedded in cryomatrix (ThermoFisher Scientific),

8 and sectioned to $6 \mu \mathrm{m}$ using a Shandon cryostat (ThermoFisher Scientific). YFP expression was

9 determined natively without the use of immunostaining. The percent of YFP+ cells was

10 determined by calculating the total area positive for YFP over the total tissue area. 8-10 images

11 per tissue were obtained with a Leica Microscope DM5500B DFC365 FX camera for analysis.

13 Immunohistochemistry \& Immunofluorescence

14 Immunohistochemistry (IHC) was performed on paraffin sections as described (Fazio et 15 al, 2017). Following antigen retrieval, sections were permeabilized with $0.2 \%$ Triton-X in PBS, 16 rinsed, then blocked in 5\% sheep serum in PBS for 1 hour at room temperature. Primary

17 antibodies were diluted in 5\% sheep serum in PBS and incubated overnight at $4^{\circ} \mathrm{C}$. Primary

18 antibodies included rabbit $\alpha$-PDX1 (1:1000; Abcam Inc. Cambridge, MA), rabbit $\alpha$-amylase

19 (1:600; Abcam Inc.), mouse $\alpha$-CK19 (1:500; Abcam Inc.) and rabbit $\alpha$-MIST1 (1:500; [53].

20 Sections were washed, then incubated in biotinylated mouse $\alpha$-rabbit IgG secondary antibody

21 (1:1000 dilution in 5\% sheep serum) for 30 minutes at room temperature. Finally, sections were

22 incubated in $\mathrm{AB}$ reagent for 30 minutes at room temperature and visualized using ImmPACT

23 DAB Peroxidase (HRP) substrate (Vector Laboratories, Cat. \#PK-4001/SK-4105). Slides were 
1 counterstained with hematoxylin and imaged using Leica Microscope DM5500B (Leica

2 Microsystems) and LAS V4.4 software.

Immunofluorescent (IF) analysis was performed on paraffin embedded tissue sections

4 similar to IHC with the exception of quenching with hydrogen peroxidase. Primary antibodies used included rabbit $\alpha$-SOX9 (1:250; Millipore Sigma), rabbit $\alpha$-Ki67 (1:250; Abcam Inc.) and rat $\alpha-F 4 / 80$ (1:200; Abcam Inc.). After washing, slides were incubated in $\alpha$-rabbit (or rat) IgG conjugated to TRITC (1:300; Jackson ImmunoResearch, West Grove, PA) or FITC (1:300;

8 Jackson ImmunoResearch) diluted in 5\% sheep serum in PBS. Prior to mounting in Vectashield

9 Permafluor mountant (Thermo Fisher Scientific), sections were incubated in DAPI (diluted

11 camera on the Leica DM5500B microscope. Images were taken on Leica LAS V4.4 software.

Protein Isolation \& Immunoblots

For whole tissue protein, pancreatic tissue was taken from the middle portion of the

15 pancreas and flash frozen in liquid nitrogen. Samples were processed as described (Young et al,

16 2018). Either $2 \mu \mathrm{g}$ (amylase) or $40 \mu \mathrm{g}$ of protein (SOX9, pERK and $\alpha$ SMA) were resolved by

17 12\% SDS-PAGE and transferred to a PVDF membrane. Western blotting was performed as

18 described [54]. For primary antibodies against [p] ERK (diluted 1:500) and total ERK (tERK;

19 diluted 1:500; Cell Signaling Technology, Danvers, MA), antibodies were diluted in 0.1\% TBST

20 with 5\% BSA. All other primary antibodies were diluted in 5\% NFDM overnight at $4{ }^{\circ} \mathrm{C}$. Primary

21 antibodies included rabbit $\alpha$-amylase [1;1000], rabbit $\alpha$-SOX9 [1:500], and rabbit $\alpha$ SMA

22 [1:500]). Secondary antibody $\alpha$-rabbit HRP was diluted 1:10,000 in 5\% NFDM (Jackson Labs).

23 Blots were incubated 1 hour at room temperature, washed, then incubated in Western ECL (Bio- 
1 Rad) substrate before being imaged on a VersaDoc system with Quantity One analysis software

2 (Bio-Rad). Protein was quantified using densitometry on ImageJ and normalized to tERK

3 accumulation.

4

7 CA) unless otherwise noted. Whole pancreas tissue was digested with agitation in $1 \mathrm{mg} / \mathrm{mL}$

8 collagenase type V (Sigma) for 15 minutes at 37 $\mathrm{oC}$ in RPMI buffer. Cell and tissue fragment

9 mixtures were filtered sequentially through 100 and 40 micron filters and washed in ice-cold

10 Maxpar PBS. Single cells were subjected to the Cell ID Cisplatinid reagent (1:2000 dilution) for

115 minutes at room temperature to identify live cells at the time of analysis. Samples were then

12 stained with a panel of surface antibodies (Supplementary Table 2) for 30 minutes at room

13 temperature according to manufacturer's instructions. Cells were washed in cell staining buffer

14 twice before cell fixation with $1.6 \%$ methanol-free formaldehyde (Thermo Fisher) for 10 minutes

15 at room temperature. Samples were transferred into Nuclear Antigen Staining Buffer for 20

16 minutes at room temperature, then washed twice with Nuclear Antigen Staining Perm prior to

17 intracellular staining. Intracellular antibodies were incubated with cells for 45 minutes at room

18 temperature. Cells were then washed twice with Nuclear Antigen Staining Perm, and twice with

19 cell staining buffer. Lastly, cells were resuspended in 1:2000 Intercalator solution in Fix and

20 Perm buffer. Samples were acquired at the University of Rochester's (New York, NY) CyTOF2

21 facility in accordance with the manufacturers protocol. 
Data was analyzed using either a Student's t-test (unpaired, two-tailed), one-way

2 ANOVA or two-way ANOVA with a Tukey's post hoc test on GraphPad Prism 6 software.

3 Repeated measures two-way ANOVA with a Tukey's post hoc test was used for weight loss over

4 time. In all cases, data is shown with individual samples and error bars representing the mean \pm

5 standard error (SE). P value $<0.05$ was considered significant.

6

$7 \quad$ Study approval

8 All animal experiments were performed according to regulations established by the

9 Animal Care and Use Committee at Western University (protocol \#2017-001). 


\section{Acknowledgements}

The authors wish to acknowledge the ongoing support of several national research

3 funding agencies for this work including the Canadian Institutes of Health Research

4 (MOP\#PJT166029), the Cancer Research Society of Canada and the Rob Lutterman Foundation

5 for Pancreatic Cancer Research. This work would not be possible without specific support from a

6 London Regional Cancer Centre Catalyst Grant, co-supported by Mr. Keith Sammit and an

7 internal bridge grant from the University of Western Ontario. NA and JT were funded by

8 studentships from the Ontario Graduate Scholarships and Cancer Research and Technology

9 Training (CaRTT) program. MK was supported by an NSERC summer studentship. JS was

10 supported by National Cancer Institute of the National Institutes of Health under award number

\section{K08CA234222.}

12

\section{Competing Interests}

14 The authors declare no competing or conflicts of interest regarding the work presented in

15 this manuscript. 


\section{$1 \quad$ References}

21 Ron D, Walter P. Signal integration in the endoplasmic reticulum unfolded protein

3 response. Nat Rev Mol Cell Biol 2007; 8: 519-529.

4

52 Kadowaki H, Nishitoh H. Signaling pathways from the endoplasmic reticulum and their $6 \quad$ roles in disease. Genes (Basel) 2013; 4: 306-333.

83 Yoshida H, Matsui T, Hosokawa N, Kaufman RJ, Nagata K, Mori K. A time-dependent 9 phase shift in the mammalian unfolded protein response. Dev Cell 2003; 4: 265-271.

10

114 Chang YS, Jalgaonkar SP, Middleton JD, Hai T. Stress-inducible gene Atf3 in the 12 noncancer host cells contributes to chemotherapy-exacerbated breast cancer metastasis.

$13 \quad$ Proc Natl Acad Sci U S A 2017; 114: E7159-E7168.

14

155 Song X, Lu F, Liu RY, Lei Z, Zhao J, Zhou Q et al. Association between the ATF3 gene 16 and non-small cell lung cancer. Thorac Cancer 2012; 3: 217-223.

17

186 Hackl C, Lang SA, Moser C, Mori A, Fichtner-Feigl S, Hellerbrand C et al. Activating transcription factor-3 (ATF3) functions as a tumor suppressor in colon cancer and is upregulated upon heat-shock protein 90 (Hsp90) inhibition. BMC Cancer 2010; 10: 668. 
17 Yan F, Ying L, Li X, Qiao B, Meng Q, Yu L et al. Overexpression of the transcription

2 factor ATF3 with a regulatory molecular signature associates with the pathogenic

3 development of colorectal cancer. Oncotarget 2017; 8: 47020-47036.

4

58 Thakur PC, Miller-Ocuin JL, Nguyen K, Matsuda R, Singhi AD, Zeh HJ et al. Inhibition

6 of endoplasmic-reticulum-stress-mediated autophagy enhances the effectiveness of

7 chemotherapeutics on pancreatic cancer. J Transl Med 2018; 16: 190.

99 Garcia-Carbonero N, Li W, Cabeza-Morales M, Martinez-Useros J, Garcia-Foncillas J.

10 New Hope for Pancreatic Ductal Adenocarcinoma Treatment Targeting Endoplasmic

11 Reticulum Stress Response: A Systematic Review. Int J Mol Sci 2018; 19.

12

1310 Chien W, Ding LW, Sun QY, Torres-Fernandez LA, Tan SZ, Xiao J et al. Selective

14 inhibition of unfolded protein response induces apoptosis in pancreatic cancer cells.

$15 \quad$ Oncotarget 2014; 5: 4881-4894.

16

1711 Hess DA, Humphrey SE, Ishibashi J, Damsz B, Lee AH, Glimcher LH et al. Extensive

18 Pancreas Regeneration Following Acinar-Specific Disruption of Xbp1 in Mice.

$19 \quad$ Gastroenterology 2011.

20

2112 Li M, Baumeister P, Roy B, Phan T, Foti D, Luo S et al. ATF6 as a transcription

22 activator of the endoplasmic reticulum stress element: thapsigargin stress-induced 
changes and synergistic interactions with NF-Y and YY1. Mol Cell Biol 2000; 20: 50965106.

413 Bertolotti A, Zhang Y, Hendershot LM, Harding HP, Ron D. Dynamic interaction of BiP and ER stress transducers in the unfolded-protein response. Nat Cell Biol 2000; 2: 326332.

814 Harding HP, Zhang Y, Ron D. Protein translation and folding are coupled by an

9 endoplasmic-reticulum-resident kinase. Nature 1999; 397: 271-274.

11 Blais JD, Filipenko V, Bi M, Harding HP, Ron D, Koumenis C et al. Activating transcription factor 4 is translationally regulated by hypoxic stress. Mol Cell Biol 2004; 24: 7469-7482.

14

1516 B'chir W, Maurin AC, Carraro V, Averous J, Jousse C, Muranishi Y et al. The

16 eIF2 $\alpha /$ ATF4 pathway is essential for stress-induced autophagy gene expression. Nucleic $17 \quad$ Acids Res 2013; 41: 7683-7699.

18

1917 Pakos-Zebrucka K, Koryga I, Mnich K, Ljujic M, Samali A, Gorman AM. The integrated stress response. EMBO Rep 2016; 17: 1374-1395. 
118 Jiang HY, Wek SA, McGrath BC, Lu D, Hai T, Harding HP et al. Activating transcription factor 3 is integral to the eukaryotic initiation factor 2 kinase stress response. Mol Cell Biol 2004; 24: 1365-1377.

4

19 Iwawaki T, Akai R, Kohno K. IRE1alpha disruption causes histological abnormality of exocrine tissues, increase of blood glucose level, and decrease of serum immunoglobulin level. PLoS One 2010; 5: e13052.

20 Iida K, Li Y, McGrath BC, Frank A, Cavener DR. PERK eIF2 alpha kinase is required to regulate the viability of the exocrine pancreas. BMC Cell Biol 2007; 8: 38.

11

1221 Kowalik AS, Johnson CL, Chadi SA, Weston JY, Fazio EN, Pin CL. Mice lacking the transcription factor Mist1 exhibit an altered stress response and increased sensitivity to caerulein-induced pancreatitis. Am J Physiol Gastrointest Liver Physiol 2007; 292: G1123-1132.

16

1722 Fazio EN, Young CC, Toma J, Levy M, Berger KR, Johnson CL et al. Activating transcription factor 3 promotes loss of the acinar cell phenotype in response to ceruleininduced pancreatitis in mice. Mol Biol Cell 2017; 28: 2347-2359.

2123 Kubisch CH, Logsdon CD. Secretagogues differentially activate endoplasmic reticulum stress responses in pancreatic acinar cells. Am J Physiol Gastrointest Liver Physiol 2007; 292: G1804-1812. 
24 Kang Y, Chen CR, Massagué J. A self-enabling TGFbeta response coupled to stress signaling: Smad engages stress response factor ATF3 for Id1 repression in epithelial cells. Mol Cell 2003; 11: 915-926.

25 Je YJ, Choi DK, Sohn KC, Kim HR, Im M, Lee Y et al. Inhibitory role of Id1 on TGF- $\beta$ induced collagen expression in human dermal fibroblasts. Biochem Biophys Res Commun 2014; 444: 81-85. approaches identify ATF3 as a negative regulator of Toll-like receptor 4. Nature 2006; 441: 173-178. obligatory role in late preconditioning via JAK-STAT signaling and upregulation of iNOS and COX-2. Cardiovasc Res 2004; 64: 61-71.

1828 Boespflug ND, Kumar S, McAlees JW, Phelan JD, Grimes HL, Hoebe K et al. ATF3 is a novel regulator of mouse neutrophil migration. Blood 2014; 123: 2084-2093.

2129 Kim DE, Procopio MG, Ghosh S, Jo SH, Goruppi S, Magliozzi F et al. Convergent roles of ATF3 and CSL in chromatin control of cancer-associated fibroblast activation. $J$ Exp Med 2017; 214: 2349-2368. 
230 Wu X, Nguyen BC, Dziunycz P, Chang S, Brooks Y, Lefort K et al. Opposing roles for calcineurin and ATF3 in squamous skin cancer. Nature 2010; 465: 368-372.

4

531 Bandyopadhyay S, Wang Y, Zhan R, Pai SK, Watabe M, Iiizumi M et al. The tumor metastasis suppressor gene Drg-1 down-regulates the expression of activating transcription factor 3 in prostate cancer. Cancer Res 2006; 66: 11983-11990.

932 Massagué J, Blain SW, Lo RS. TGFbeta signaling in growth control, cancer, and heritable disorders. Cell 2000; 103: 295-309.

11

1233 Song HM, Park GH, Eo HJ, Jeong JB. Naringenin-Mediated ATF3 Expression

13 Contributes to Apoptosis in Human Colon Cancer. Biomol Ther (Seoul) 2016; 24: 140146.

1634 Kim KJ, Lee J, Park Y, Lee SH. ATF3 Mediates Anti-Cancer Activity of Trans-10, cis12-Conjugated Linoleic Acid in Human Colon Cancer Cells. Biomol Ther (Seoul) 2015; 23: 134-140.

2035 Johnson CL, Kowalik AS, Rajakumar N, Pin CL. Mist1 is necessary for the establishment of granule organization in serous exocrine cells of the gastrointestinal tract. Mech Dev 2004; 121: 261-272. 
136 Tsuda M, Fukuda A, Roy N, Hiramatsu Y, Leonhardt L, Kakiuchi N et al. The BRG1/SOX9 axis is critical for acinar cell-derived pancreatic tumorigenesis. J Clin Invest 2018; $128:$ 3475-3489.

4 2013; 32: 1950-1958.

938 Yadav D, Lowenfels AB. The epidemiology of pancreatitis and pancreatic cancer. Gastroenterology 2013; 144: 1252-1261.

11

1239 Kopp JL, Dubois CL, Schaffer AE, Hao E, Shih HP, Seymour PA et al. Sox9+ ductal cells are multipotent progenitors throughout development but do not produce new

1640 Pin CL, Rukstalis JM, Johnson C, Konieczny SF. The bHLH transcription factor Mist1 is 17 required to maintain exocrine pancreas cell organization and acinar cell identity. J Cell Biol 2001; 155: 519-530. 30: $2669-2683$. 
142 Pinho AV, Rooman I, Reichert M, De Medts N, Bouwens L, Rustgi AK et al. Adult pancreatic acinar cells dedifferentiate to an embryonic progenitor phenotype with concomitant activation of a senescence programme that is present in chronic pancreatitis. Gut 2011; 60: 958-966.

43 Carrière C, Young AL, Gunn JR, Longnecker DS, Korc M. Acute pancreatitis accelerates initiation and progression to pancreatic cancer in mice expressing oncogenic Kras in the nestin cell lineage. PLoS One 2011; 6: e27725.

1044 Delous M, Yin C, Shin D, Ninov N, Debrito Carten J, Pan L et al. Sox9b is a key

11 regulator of pancreaticobiliary ductal system development. PLoS Genet 2012; 8:

$12 \quad \mathrm{e} 1002754$

13

1445 Prevot PP, Simion A, Grimont A, Colletti M, Khalaileh A, Van den Steen G et al. Role of 15 the ductal transcription factors HNF6 and Sox9 in pancreatic acinar-to-ductal metaplasia.

$16 \quad$ Gut.

1846 Gardian K, Janczewska S, Olszewski WL, Durlik M. Analysis of pancreatic cancer 
147 Kurahara H, Shinchi H, Mataki Y, Maemura K, Noma H, Kubo F et al. Significance of M2-polarized tumor-associated macrophage in pancreatic cancer. J Surg Res 2011; 167: e211-219.

4

48 Helm O, Held-Feindt J, Grage-Griebenow E, Reiling N, Ungefroren H, Vogel I et al. they impact on pancreatic tumorigenesis. Int J Cancer 2014; 135: 843-861.

949 Mallano T, Palumbo-Zerr K, Zerr P, Ramming A, Zeller B, Beyer C et al. Activating transcription factor 3 regulates canonical TGF $\beta$ signalling in systemic sclerosis. Ann Rheum Dis 2016; 75: 586-592.

1350 Clark CE, Hingorani SR, Mick R, Combs C, Tuveson DA, Vonderheide RH. Dynamics of the immune reaction to pancreatic cancer from inception to invasion. Cancer Res 2007; 67: 9518-9527.

16

1751 Harding HP, Zhang Y, Zeng H, Novoa I, Lu PD, Calfon M et al. An integrated stress

2152 Hingorani SR, Petricoin EF, Maitra A, Rajapakse V, King C, Jacobetz MA et al. 2003; 11: 619-633. 
253 Pin CL, Bonvissuto AC, Konieczny SF. Mist1 expression is a common link among serous exocrine cells exhibiting regulated exocytosis. Anat Rec 2000; 259: 157-167.

4

554 Young CC, Baker RM, Howlett CJ, Hryciw T, Herman JE, Higgs D et al. The Loss of ATRX Increases Susceptibility to Pancreatic Injury and Oncogenic KRAS in Female But Not Male Mice. Cell Mol Gastroenterol Hepatol 2019; 7: 93-113. 


\section{Figure Legends}

3 Figure 1. Atf3 - mice show accelerated pancreatic regeneration in response to recurrent

4 pancreatic injury. (A) Quantification of pancreatic weight as a \% of body weight in mice treated

5 with saline (Sal) or cerulein (rCIP) one and seven days after cessation of treatment. Cerulein-

6 treated wild type (WT) and Atf3-/ mice showed significant decrease in pancreatic weight at Day

71 with no significant difference between genotypes. Seven days into recovery, only cerulein-

8 treated WT mice showed a decrease in pancreatic weight relative to other groups. (B)

9 Representative H\&E histology shows loss of acinar tissue and increased number of duct-like

10 structures one day after rCIP in both genotypes. By day 7 after rCIP, there is reduced damage

11 and increased acinar cell area in Atf3 - tissue compared to WT tissue. Magnification bars $=100$

$12 \mu \mathrm{m}$. (C) Immunohistochemistry (IHC) for amylase in WT and Atf3-љ pancreatic tissue from mice

13 treated with saline or 1 or 7 days following rCIP. Magnification bar $=400 \mu \mathrm{m}$. (D) Western blot

14 analysis and quantification of amylase accumulation in pancreatic extracts from mice treated

15 with saline (-) or rCIP (+). In all cases, ns, not significant; *p<0.05, **p<0.01, \#p $<0.001 ; \mathrm{N}$

16 values are indicated above the data points; error bars represent mean \pm SEM. To determine

17 significance, a two-way ANOVA was performed with a Tukey’ post-hoc test.

19 Figure 2. Atf3-/ mice exhibit reduced ADM in response to recurrent pancreatic injury.

20 (A) Quantification of ADM-like structures following rCIP based on H\&E analysis. A significant

21 increase in putative ADM structures was observed one day after rCIP in both genotypes, but no

22 difference between genotypes in the rCIP cohorts. 7 days after rCIP treatment, significantly

23 fewer putative ADM structures were observed in rCIP-treated Atf3-/- mice compared wild type 
1 (WT). (B) Representative IHC for CK19 in WT and Atf3-/ pancreatic tissue following saline or rCIP. Magnification bars $=70 \mu \mathrm{m}$. (C) Quantification of CK19 IHC revealed decreased CK19

3 accumulation one and seven days after rCIP in Atf3 «- mice relative to WT mice. In all cases, N

4 values are indicated above the data points; ns, not significant; $* \mathrm{p}<0.05 ;{ }^{* *} \mathrm{p}<0.01, \# \mathrm{p}<0.001$;

5 error bars represent mean \pm SEM. To determine significance, a two-way ANOVA was

6 performed with a Tukey' post-hoc test.

8 Figure 3. The ADM transcriptional program is reduced in the absence of ATF3.

9 (A) Representative IF for SOX9 in WT and Atf3-^ pancreatic tissue from mice 1 or 7 days

10 following saline or rCIP treatment. Sections were counterstained with DAPI to reveal nuclei.

11 Arrow indicate SOX9+ cells. Magnification bars $=20 \mu \mathrm{m}$. (B) Quantification of the percentage

12 of SOX9+ nuclei showed significantly fewer cells express SOX9 in Atf3- tissue at both time

13 points. (C) Representative IHC for MIST1 in WT and Atf3-/ pancreatic tissue 1 or 7 days

14 following saline or rCIP. Arrowheads indicate MIST1+ cells. Magnification bars $=50 \mu \mathrm{m}$. (D)

15 Quantification of the percent MIST1+ nuclei confirm significantly fewer cells express MIST1 in

16 Atf3-- tissue. For graphs, $\mathrm{N}$ values are indicated above data points; ns, not significant; *p<0.05,

$17 \# \mathrm{p}<0.001$; error bars represent mean \pm SEM. To determine significance, a two-way ANOVA was

18 performed with a Tukey' post-hoc test.

20 Figure 4. Atf3 - mice show minimal spontaneous ADM and PanIN formation following

21 activation of oncogenic KRAS. (A) Quantification of pancreatic weight as a \% of body weight

2213 weeks after activation of KRASG12D with tamoxifen. Pancreatic weight is increased in

$23 P t f l a_{c r e E R T /+K r a s G 12 D /+}$ (indicated as KRASG12D) mice relative to wild type (WT), 
1 PtflacreERT/+Atf3-/ and APK mice. (B) Representative H\&E on pancreatic tissue from

$2 P t f l a_{c r e E R T /+K r a s G 12 D /+}$ and $A P K$ mice 13 weeks after KRASG12D activation. Extensive lesions

3 were observed in 2/5 PtflacreERT/+KrasG12D/+ mice but not in any other genotype. Magnification

4 bars $=100 \mu \mathrm{m}$. (C) Quantification of lesion area based on H\&E histology. Lesion area was

5 increased in PtflacreERT/+KrasG12D/+ tissue relative to all other genotypes. For all graphs, $\mathrm{N}$ values

6 are indicated above data points; ns, not significant; * ${ }^{*}<0.05$; error bars represent mean \pm SEM.

7 To determine significance, a one-way ANOVA was performed with a Tukey' post-hoc test. (D)

8 Representative IF for SOX9 (red) on pancreatic tissue for each genotype. Sections were

9 counterstained with DAPI to reveal nuclei. Magnification bars $=60 \mu \mathrm{m}$.

11 Figure 5. ATF3 is dispensable for progression but not maintaining PanINs when KRASG12D

12 activation is coupled with pancreatic injury. Representative H\&E histology on pancreatic tissue

13 (A) two and (B) five weeks after cerulein treatment for all genotypes. No lesions were observed

14 in WT or Atf3-_-Ptfla $a_{c r e E R T /+}$ tissue. Extensive lesions and no acinar tissue was visible at either

15 time point in both PtflacreERT/+KrasG12D/+ (KRASG12D) and APK tissue following cerulein

16 treatment. Magnification bars $=100 \mu \mathrm{m}$. (C) Representative Alcian blue histology on

$17 P t f l a_{c r e E R T /+} \operatorname{rasG12D/+}$ and $A P K$ tissue following cerulein treatment showed significantly more

18 alcian blue staining in PtflacreERT/+KrasG12D/+ mice which is quantified in (D). (E) Representative

19 IF for Ki-67 in PtflacreERT/+KrasG12D/+ and APK tissue 2 and 5 weeks following cerulein

20 treatment. Magnification bar $=50 \mu \mathrm{m}$. (F) Quantification of the percentage of Ki-67+ cells

21 indicated significantly fewer positive cells in $A P K$ tissue. For all graphs, $\mathrm{N}$ values are indicated

22 in brackets or above data points; ns, not significant; ${ }^{*} \mathrm{p}<0.05, \# \mathrm{p}<0.001$; error bars represent

23 mean \pm SEM. To determine significance, a student's t-test (D) or (F) two-way ANOVA was 
1 performed with a Tukey' post-hoc test.

3 Figure 6. ATF3 is required for complete establishment and maintenance of the molecular ADM

4 profile in the presence of KRASG12D. (A) Representative western blots for amylase (AMY),

5 SOX9, phosphorylated ERK (pERK) and total ERK (tERK, loading control). No detectable

6 amylase accumulation is observed in PtflacreERT/+KrasG12D/+ or APK tissue (quantified in B)

7 while SOX9 and pERK accumulation increases only in PtflacreERT/+KrasG12D/+ tissue (quantified

8 in $\mathrm{C}$ and $\mathrm{E}$, respectively). Similar results are obtained both 2 and 5 weeks after cerulein (CIP)

9 treatment. For all graphs, $\mathrm{N}$ values are indicated above data points; significantly different values

10 are indicated by letters. In (C) and (E), PtflacreERT/+KrasG12D/+ values are significantly different

11 from all genotypes $(\mathrm{p}<0.001)$ even from $A P K$ mice $(\mathrm{p}<0.05)$. Error bars represent mean \pm

12 SEM. To determine significance, a two-way ANOVA was performed with a Tukey' post-hoc

13 test. (D) Representative IF for SOX9 (red) on pancreatic tissue from PtflacreERT/+KrasG12D/+ or

$14 A P K$ mice. Sections were counterstained with DAPI to reveal nuclei. Magnification bars $=20$

$15 \mu \mathrm{m}$.

17 Figure 7. APK mice display enhanced fibrosis at early time point after pancreatic injury.

18 Representative images of Mason trichrome staining (A) two or (B) five weeks after cerulein

19 treatment in all genotypes. Magnification bars $=140 \mu \mathrm{m}$. (C) Quantification of fibrosis based on

20 trichrome staining, showed increased fibrosis in $A P K$ tissue compared to all other genotypes two

21 weeks post-CIP and increased fibrosis in Ptfla $a_{c r e E R T /+}$ KrasG12D/+ $\left(K R A S_{G 12 D}\right)$ and APK mice five

22 weeks after cerulein treatment. $\mathrm{N}$ values are indicated above data points; ns, not significant;

$23 * \mathrm{p}<0.05, \# \mathrm{p}<0.001$; error bars represent mean \pm SEM. To determine significance, a one-way 
1 ANOVA was performed with a Tukey' post-hoc test.

3 Figure 8. APK mice showed an altered inflammatory response to pancreatic damage.

4 (A) Representative viSNE analysis performed on cytometric flow data obtained from

$5 P t f l a_{c r e E R T /+K r a s G 12 D /+}\left(K R A S_{G 12 D}\right)$ and $A P K$ mice pancreata at 2 weeks post CIP (n=3-4). (B)

6 Quantification of macrophage and CD4 T cells based on viSNE analysis suggested decreased

7 macrophage and increased $\mathrm{T}$ lymphocyte accumulation in $A P K$ pancreata relative to

8 PtflacreERT/+KrasG12D/+. (C) Representative IF images show significant fewer macrophages based

9 on the percent area or F4/80 staining F4/80 in $A P K$ mice, which is quantified in (D). ${ }^{*} \mathrm{P}<0.05$,

10 error bars represent $\%$ mean $\pm \mathrm{SEM} ; \mathrm{N}=3$. To determine significance, a student's t-test was

11 performed.

12

13 
1 Table 1. Histological analysis of pancreatic lesions in response to saline or cerulein treatment 1

\begin{tabular}{|c|c|c|c|c|c|c|c|c|}
\hline \multirow[b]{2}{*}{ Saline } & \multicolumn{2}{|c|}{ Ptfla } & \multicolumn{2}{|c|}{ Atf3-_Ptf1a } & \multicolumn{2}{|c|}{ Ptf1a ${ }_{c r e E R T /+K R A} S_{G 12 D /+}$} & \multicolumn{2}{|c|}{$A P K$} \\
\hline & 2 weeks & 5 weeks & 2 weeks & 5 weeks & 2 weeks & 5 weeks & 2 weeks & 5 weeks \\
\hline Normal & 4 & 2 & 3 & 2 & 1 & 0 & 1 & 1 \\
\hline ADM & 0 & 1 & 0 & 0 & 0 & 0 & 1 & 0 \\
\hline PanIN1 & 0 & 0 & 0 & 0 & 2 & 2 & 1 & 1 \\
\hline PanIN2 & 0 & 0 & 0 & 0 & 0 & 1 & 0 & 1 \\
\hline PanIN3 & 0 & 0 & 0 & 0 & 0 & 0 & 0 & 0 \\
\hline PDAC & 0 & 0 & 0 & 0 & 0 & 0 & 0 & 0 \\
\hline $\begin{array}{l}\text { Total \# } \\
\text { of mice }\end{array}$ & 4 & 3 & 3 & 2 & 3 & 3 & 3 & 3 \\
\hline
\end{tabular}

Cerulein

\begin{tabular}{lllllllll}
\hline Normal & 0 & 2 & 2 & 0 & 0 & 0 & 0 & 0
\end{tabular}

$\begin{array}{lllllllll}\text { ADM } & 2 & 0 & 0 & 1 & 0 & 0 & 0 & 0 \\ \text { PanIN1 } & 0 & 0 & 1 & 0 & 0 & 0 & 2 & 1 \\ \text { PanIN2 } & 0 & 0 & 0 & 0 & 2 & 2 & 0\end{array}$

\begin{tabular}{lllllllll} 
PanIN2 & 0 & 0 & 0 & 0 & 2 & 2 & 0 & 5 \\
PanIN3 & 0 & 0 & 0 & 0 & 9 & 4 & 4 & 2 \\
PDAC & 0 & 0 & 0 & 0 & 1 & 1 & 0 & 0 \\
\hline Total \# & 2 & 2 & 3 & 1 & 12 & 7 & 6 & 8
\end{tabular}

21 - pancreatic tissue was scored for the highest grade lesion within the tissue. Numbers do not include three

$3 P t f l a_{c r e E R T /+} K R A S_{G I 2 D /+}$ and one $A P K$ mouse that needed to be sacrificed prior to the experimental end point 
bioRxiv preprint doi: https://doi.org/10.1101/2020 03.27.011601; this version posted March 29, 2020. The copyright holder for this preprint (which was not certified by peer review) is the author/funder, who has granted bioRxiv a license to display the preprint in perpetuity. It is made available under aCC-BY-NC-ND 4.0 International license.

A
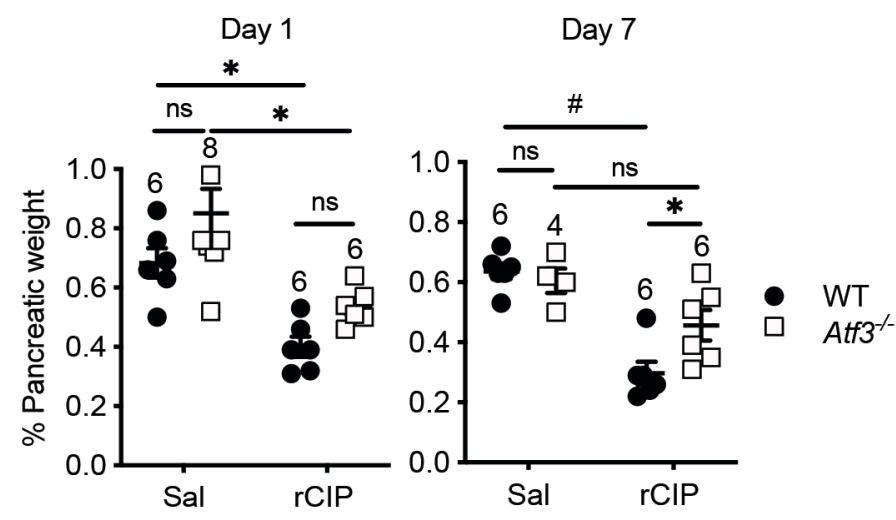

B
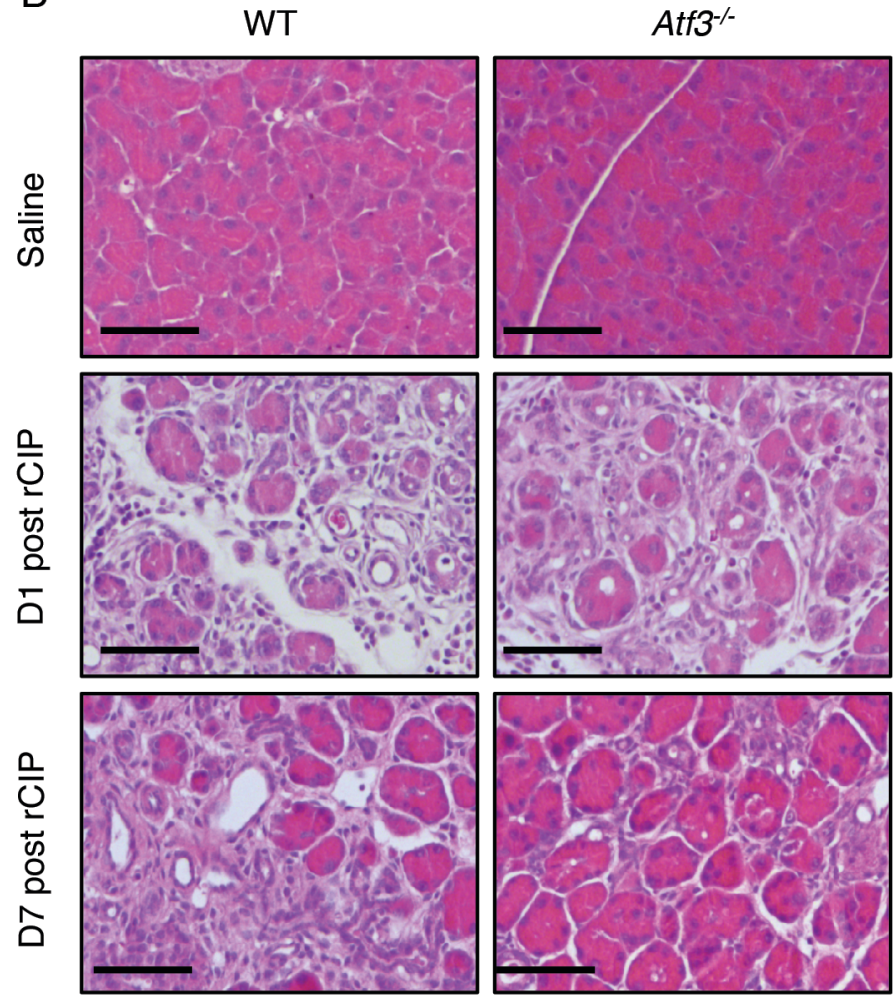

C
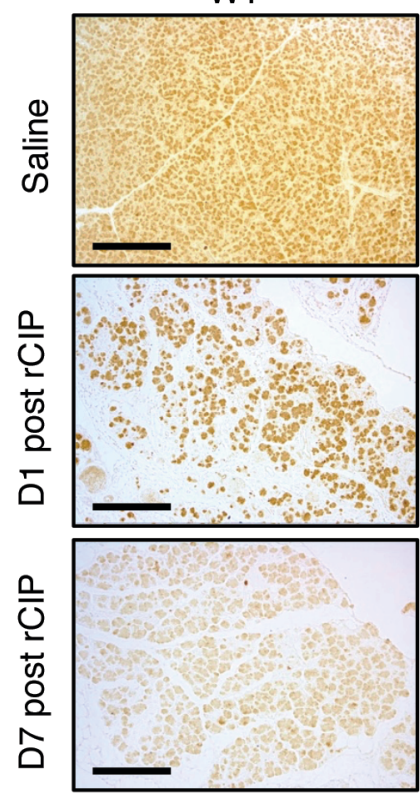

D
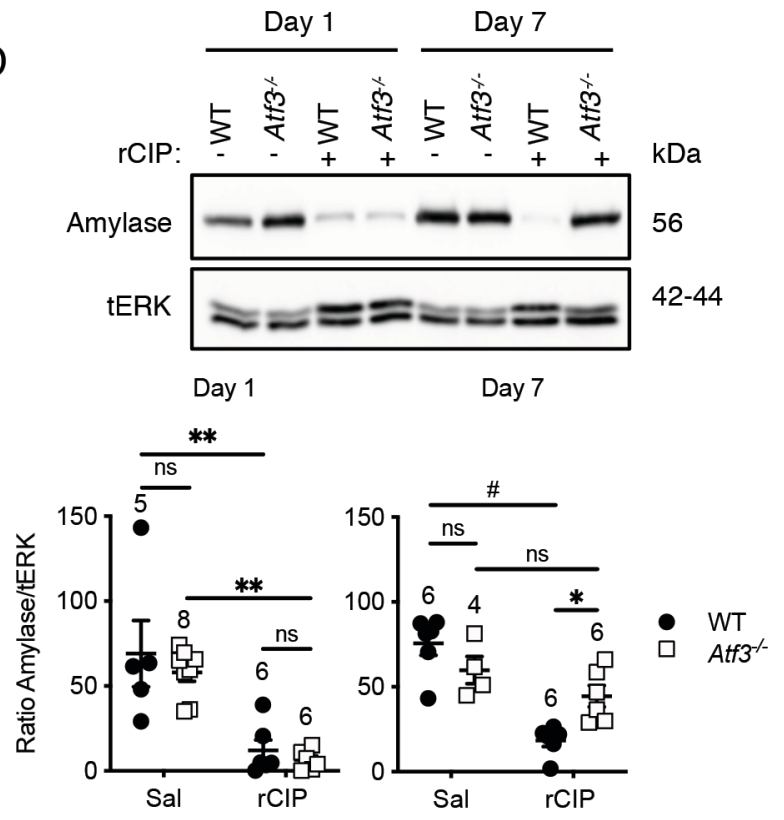

Azizi et al (2019) Figure 1. 

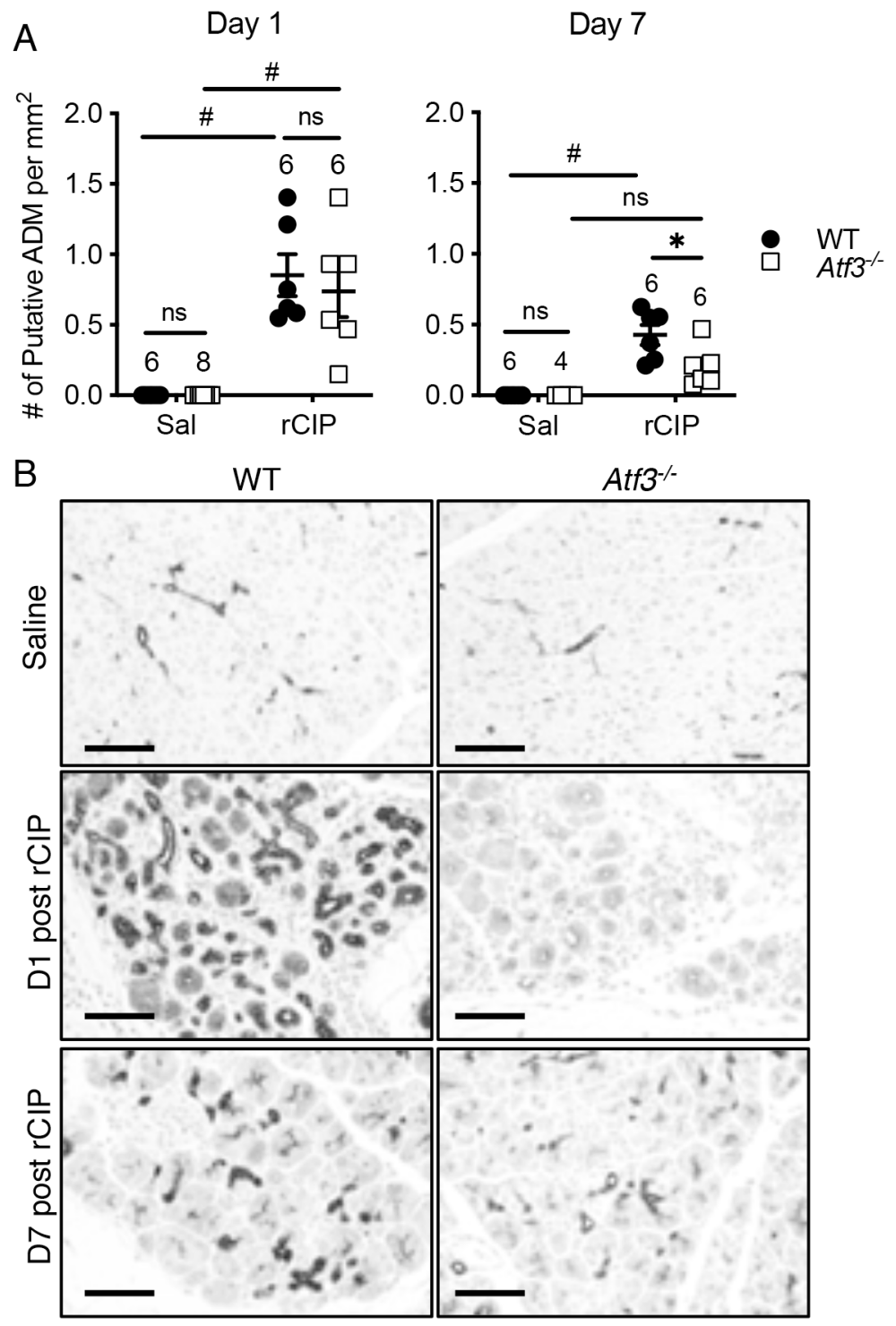

C

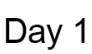

Day 7
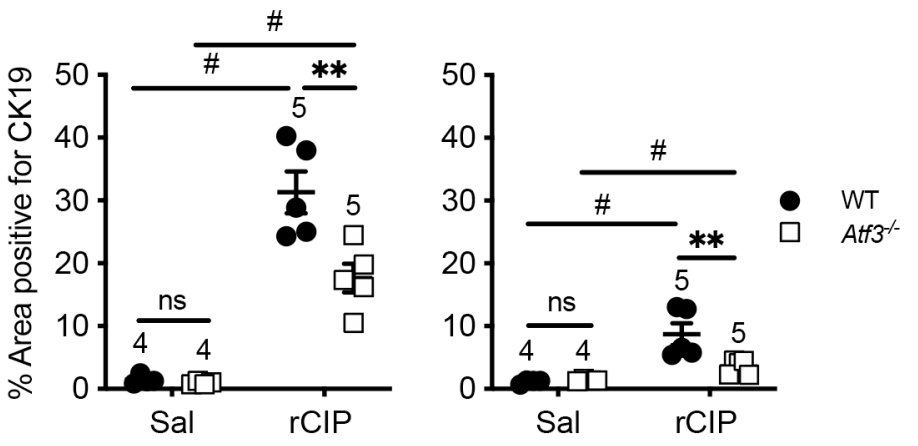

Azizi et al (2019). Figure 2 
bioRxiv preprint doi: https://doi.org/10.1101/2020.03.27.011601; this version posted March 29, 2020. The copyright holder for this preprint (which was not certified by peer review) is the author/funder, who has granted bioRxiv a license to display the preprint in perpetuity. It is made available under aCC-BY-NC-ND 4.0 International license.

A
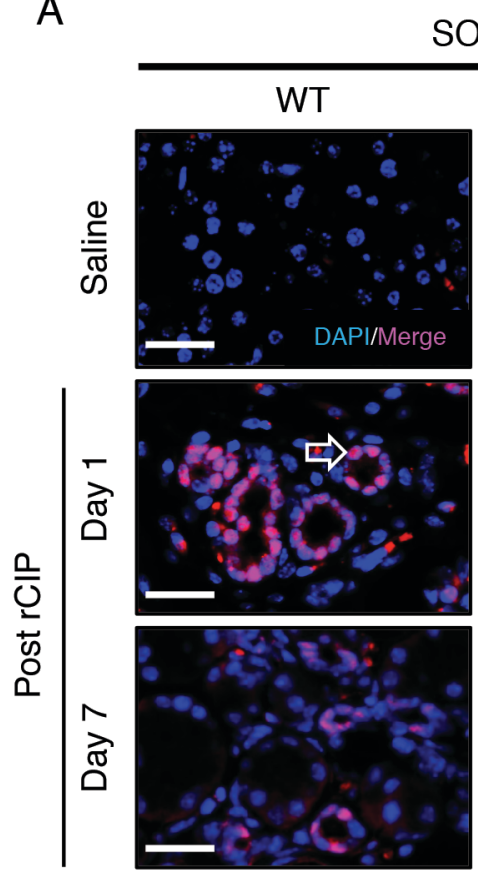

B

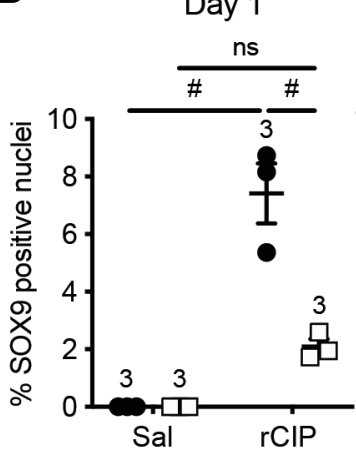

SOX9
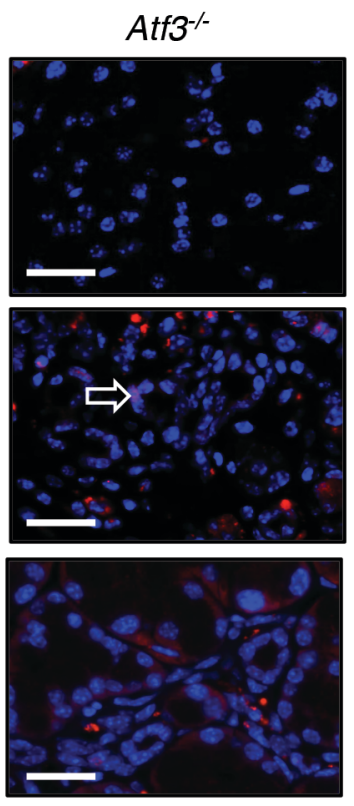

Day 7

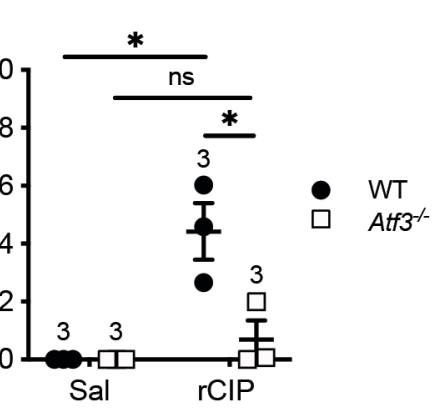

C
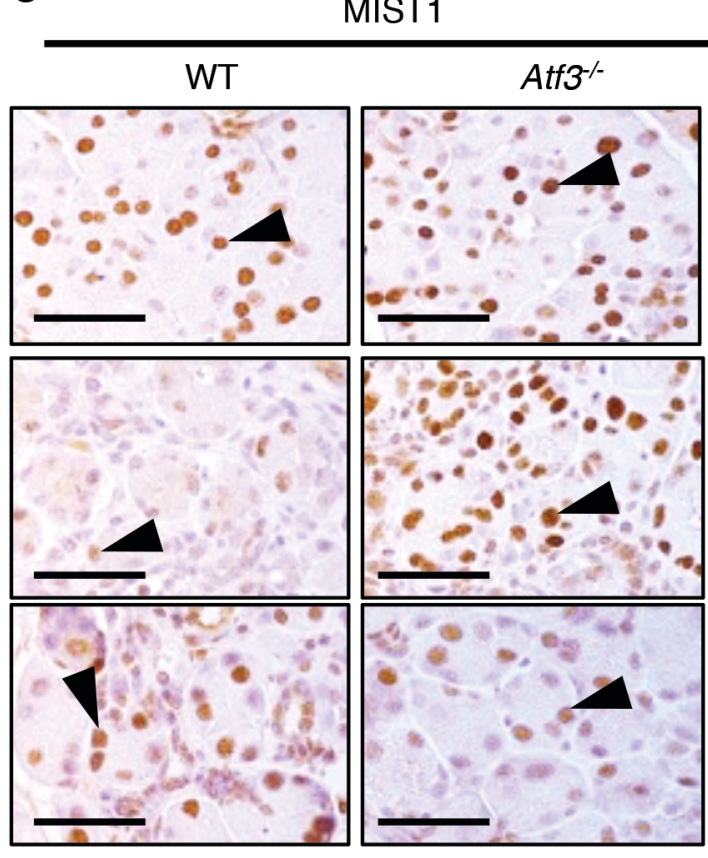

D

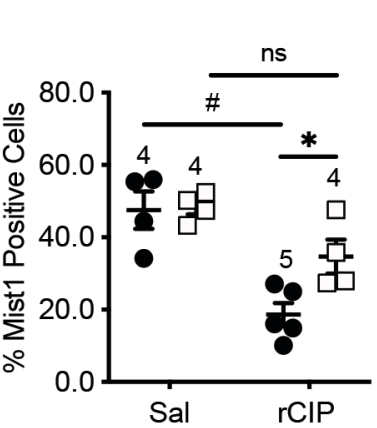

Day 7
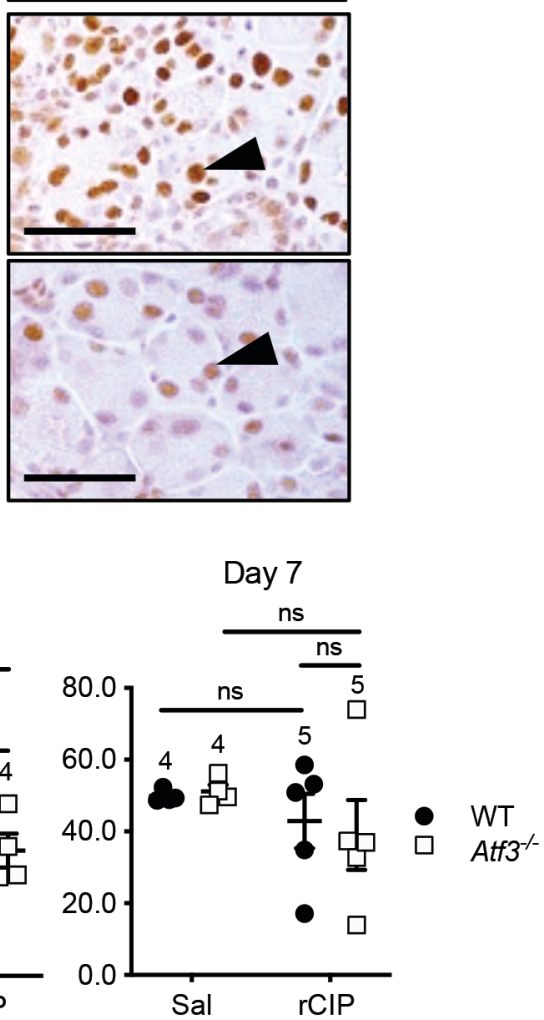

Azizi et al (2019) Figure 3 
bioRxiv preprint doi: $h t t p s: / / d o i . o r g / 10.1101 / 2020.0327 .011601$; this version posted March 29, 2020. The copyright holder for this preprint (which was not certified by peer review) is the author/funder, who has granted bioRxiv a license to display the preprint in perpetuity. It is made available under aCC-BY-NC-ND 4.0 International license.
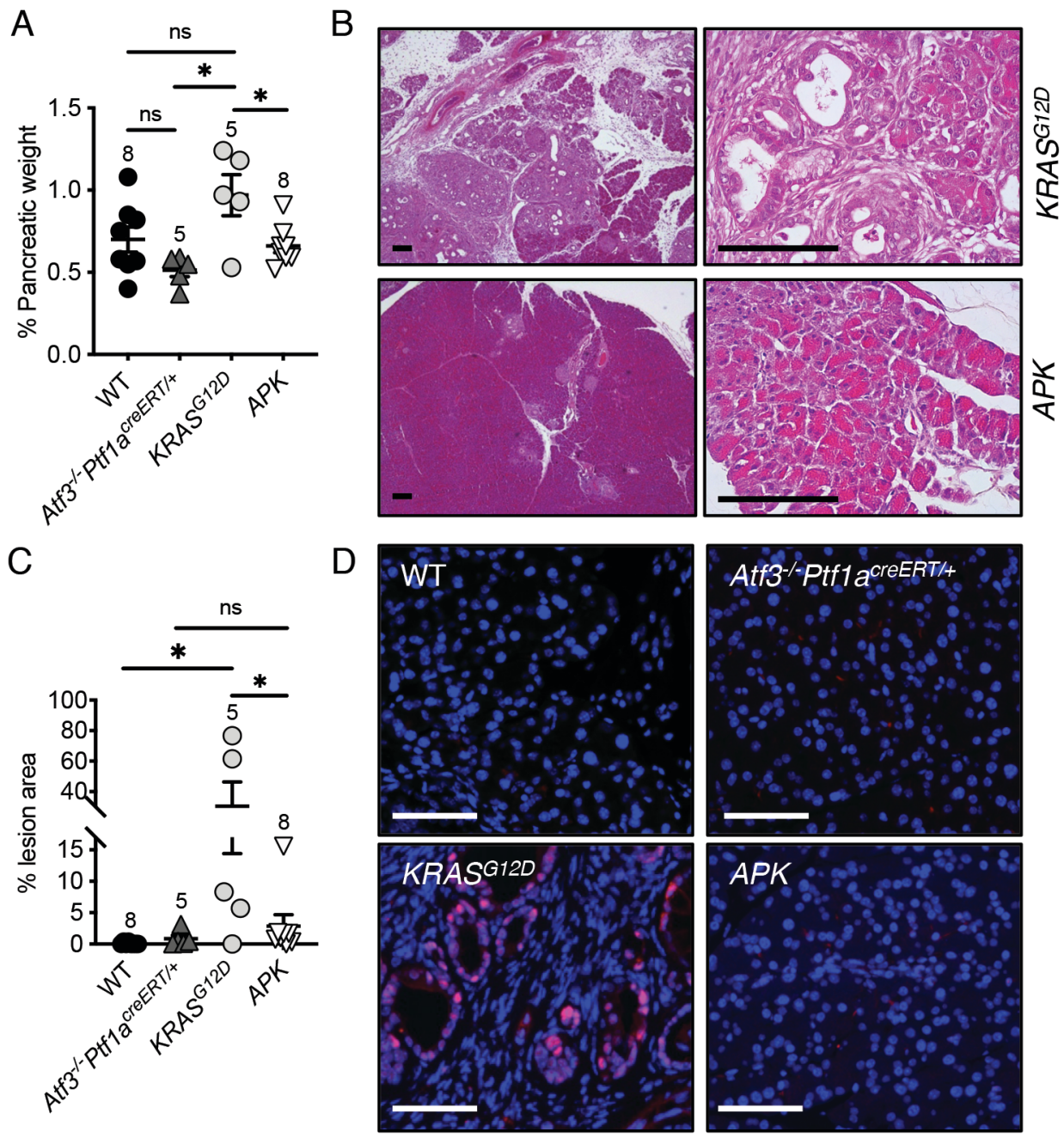

Azizi et al (2019). Figure 4. 
bioRxiv preprint doi: https://doi.org/10.1101/2020.03.27.011601; this version posted March 29, 2020. The copyright holder for this preprint (which was not certified by peer review) is the author/funder, who has granted bioRxiv a license to display the preprint in perpetuity. It is made available under aCC-BY-NC-ND 4.0 International license.

A
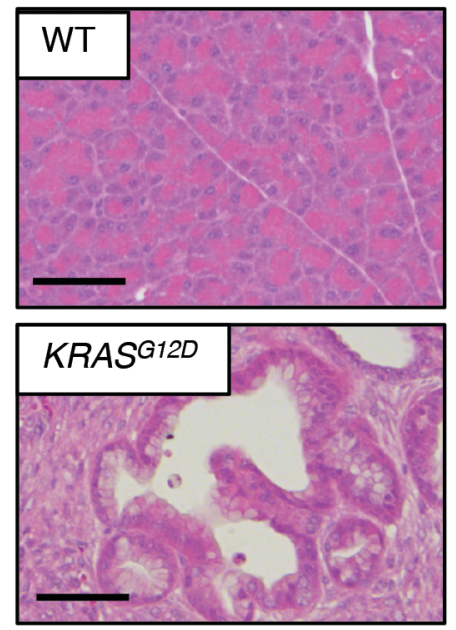

C

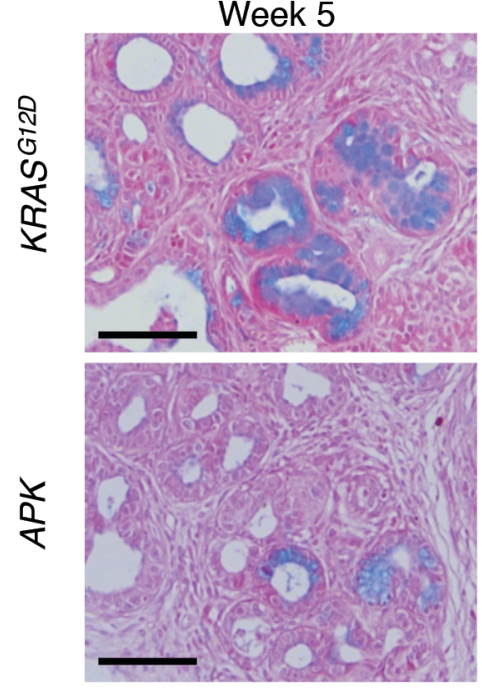

D

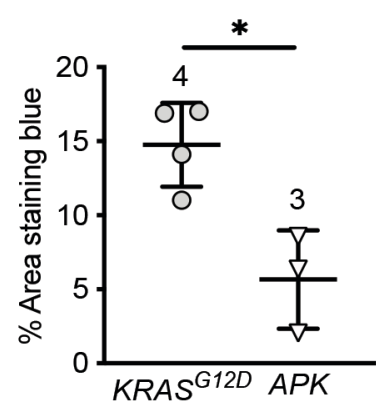

B
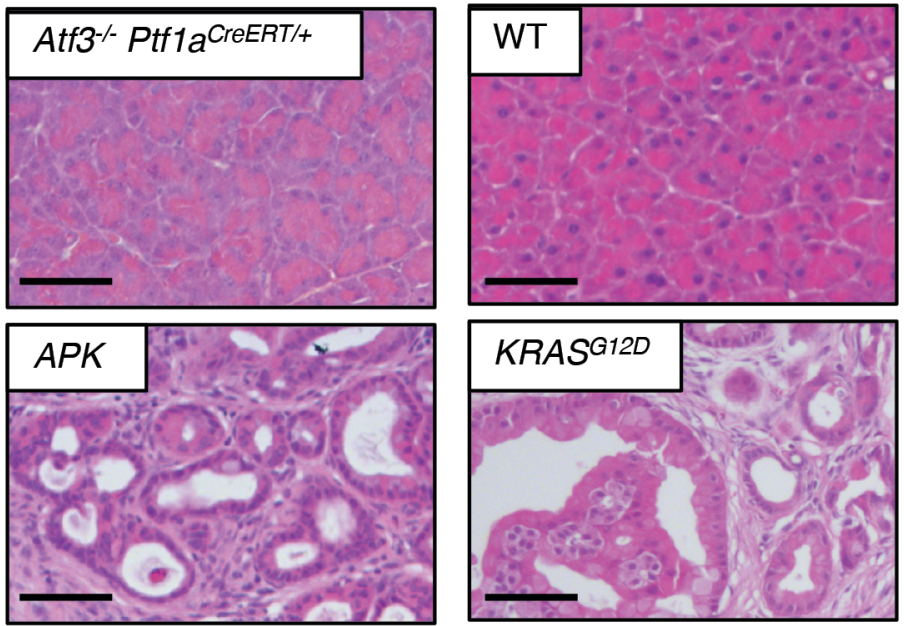

E

Week 2
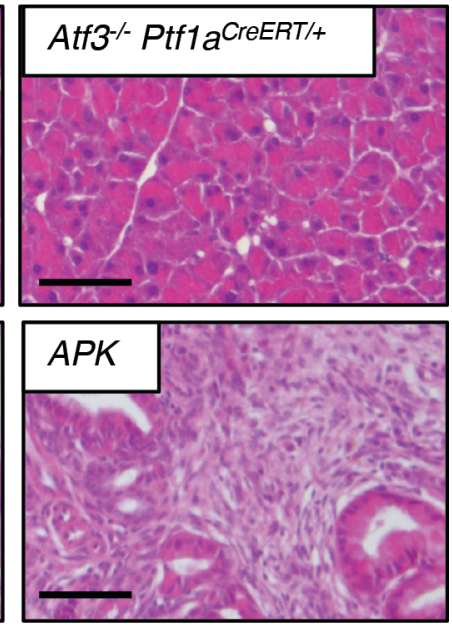

Week 5
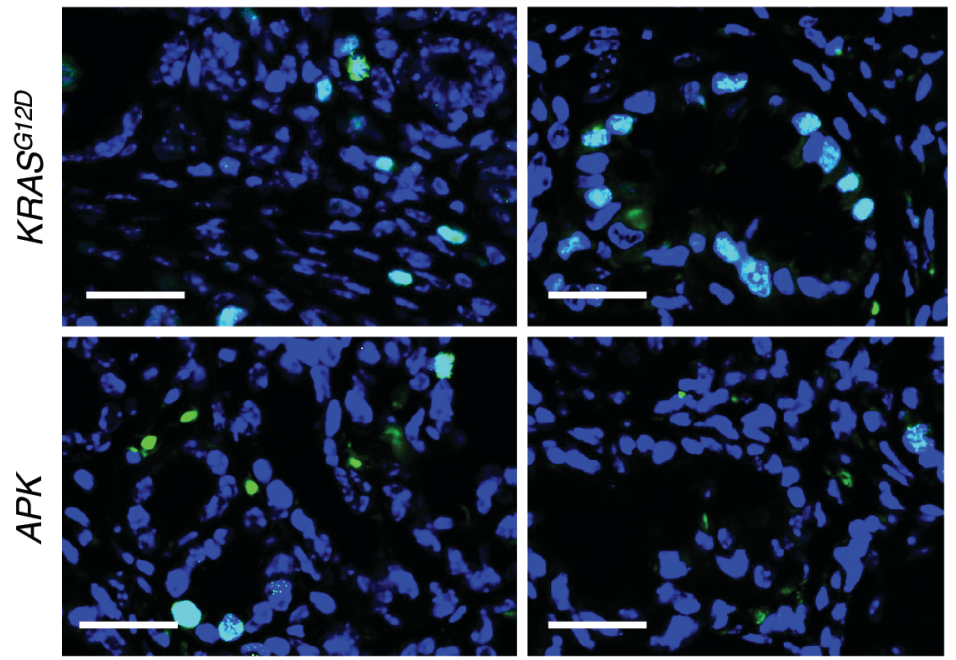

F

Week 2
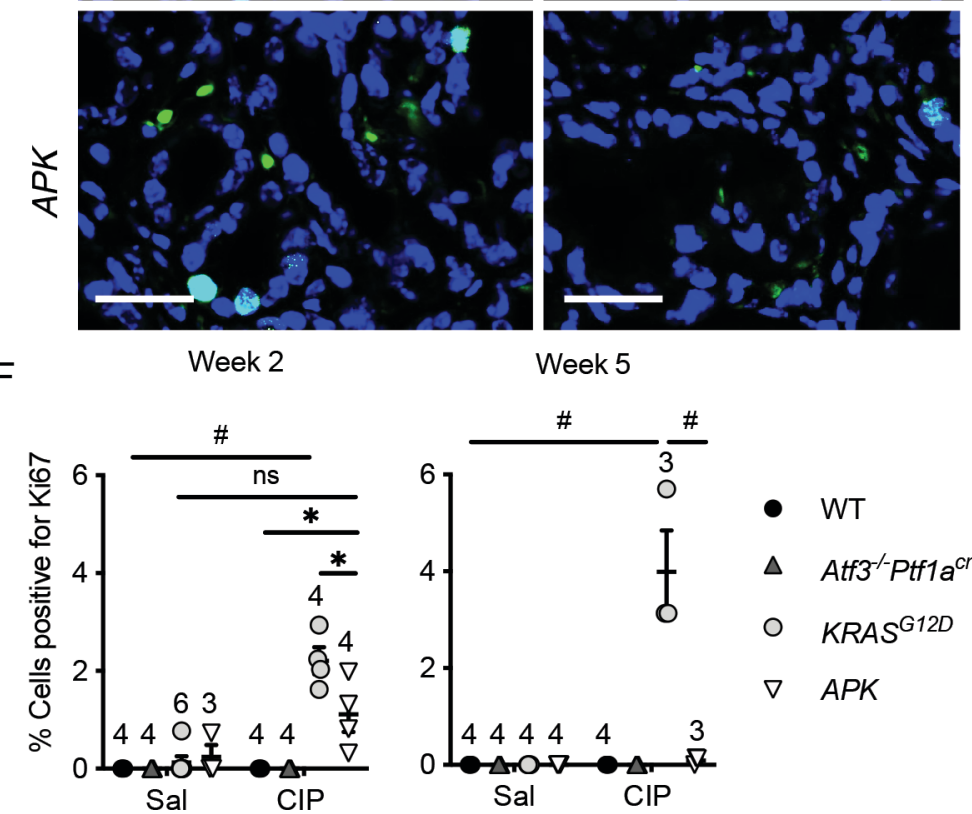

- WT

$\triangle \quad$ Atf3 $^{-}-\mathrm{Ptf1} \mathrm{a}^{\mathrm{creERT/+}}$

O KRAS ${ }^{G 12 D}$

$\nabla \quad A P K$

Azizi et al (2019) Figure 5. 
A

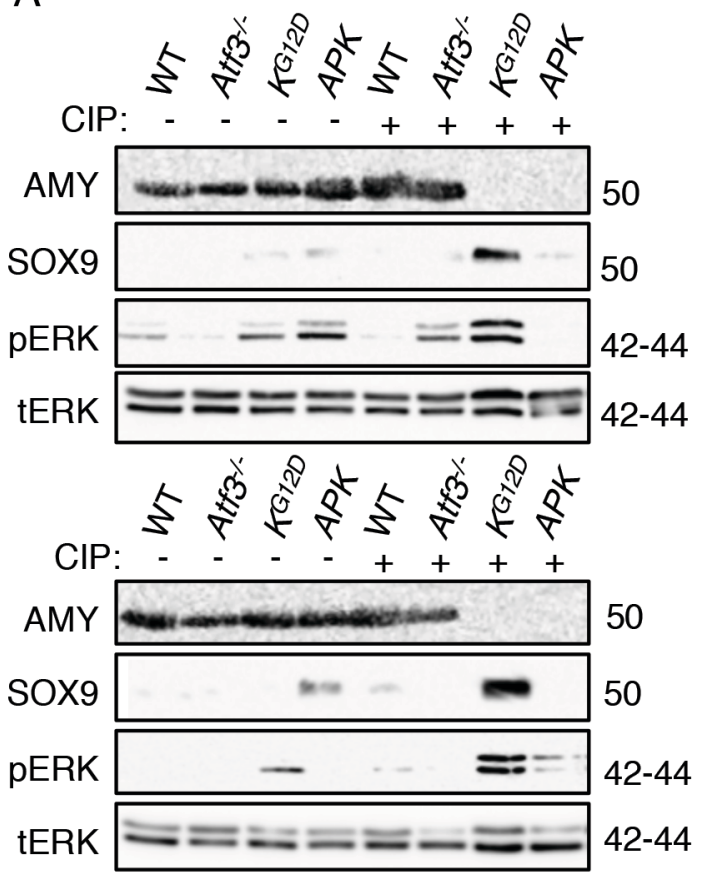

D
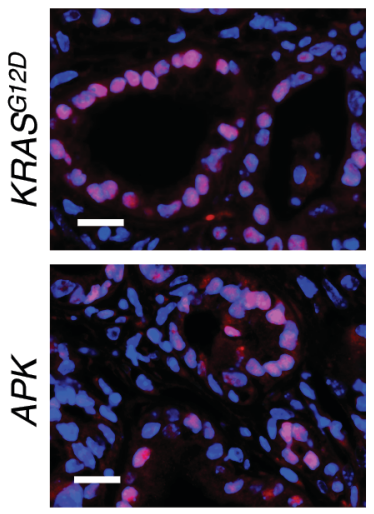

B

Week 2

Week 5

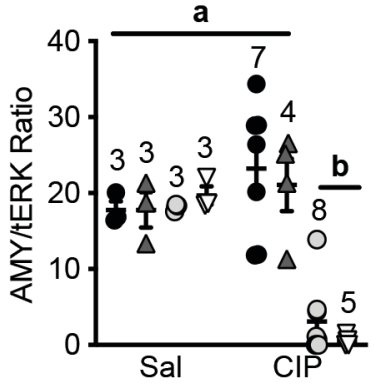

C Week 2
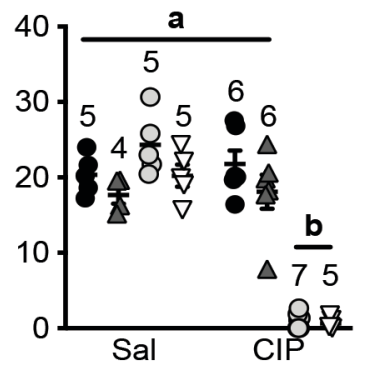

- WT

$\triangle \quad A_{t f 3}{ }^{-1-} P t f 1 a^{\text {creERT/+ }}$ KRAS ${ }^{G 12 D}$ $A P K$

Week 5
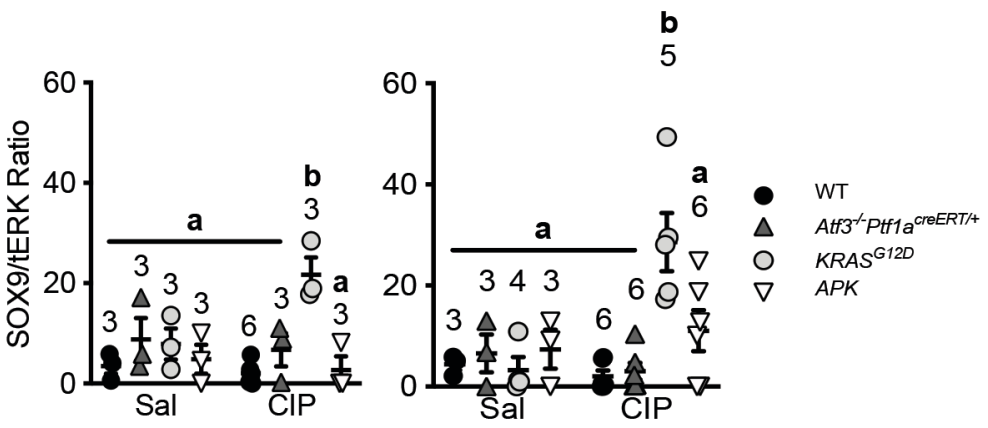

E

Week 2

Week 5

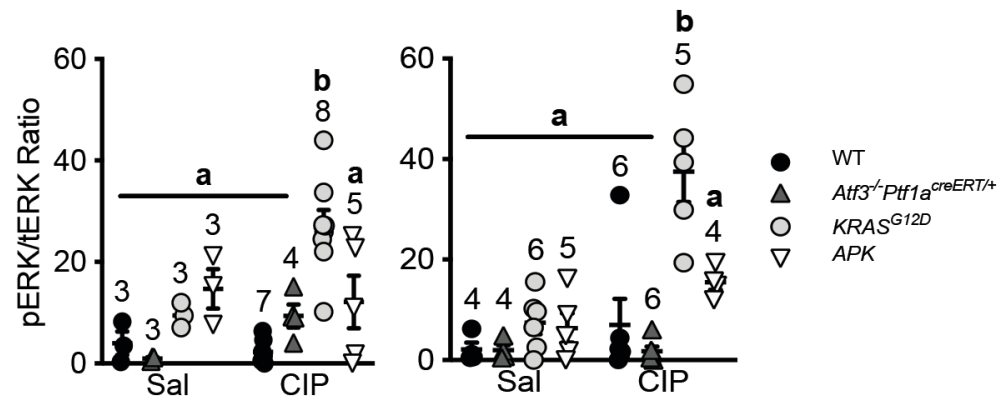

Azizi et al (2019) Figure 6. 


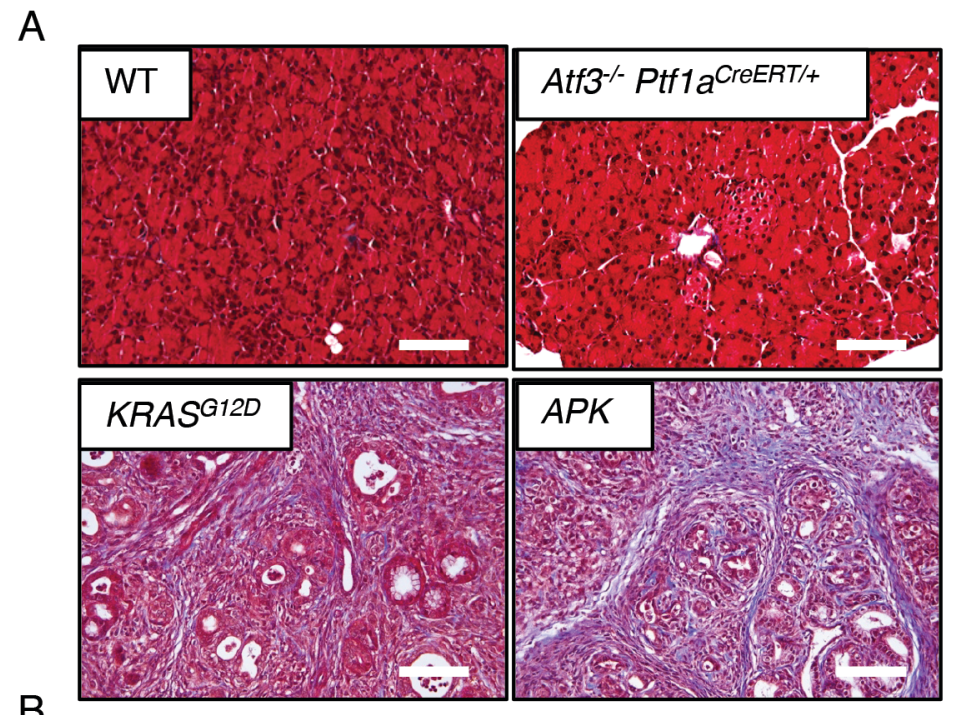

B
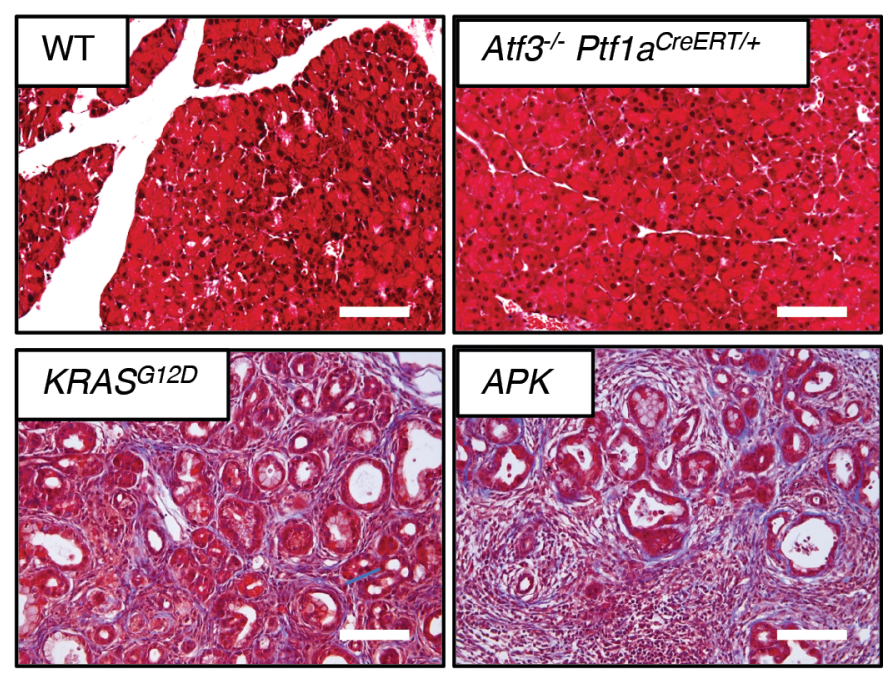

C

Week 2

Week 5
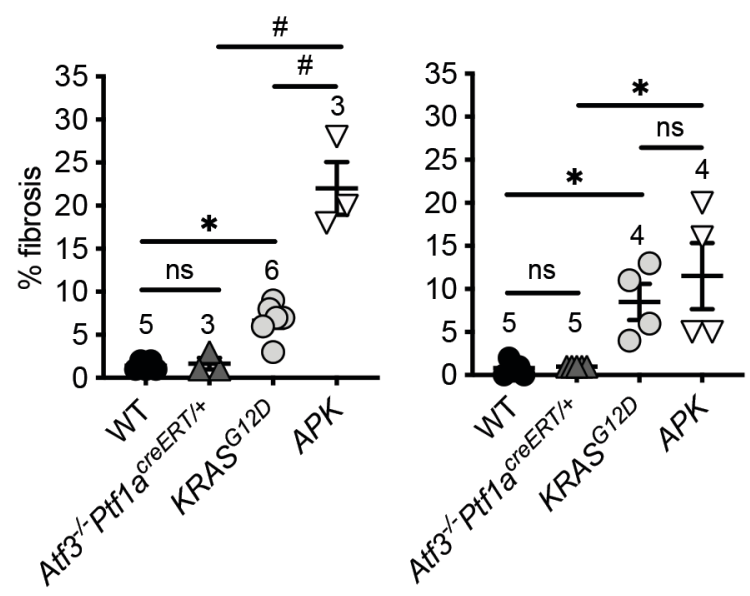

Azizi et al (2019). Figure 7. 
bioRxiv preprint doi: $\mathrm{https}$ //doi.org/10.1101/2020 0327.011601 ; this version posted March 29,2020 . The copyright holder for this preprint (which was not certified by peer review) is the author/funder, who has granted bioRxiv a license to display the preprint in perpetuity. It is made available under aCC-BY-NC-ND 4.0 International license.

A
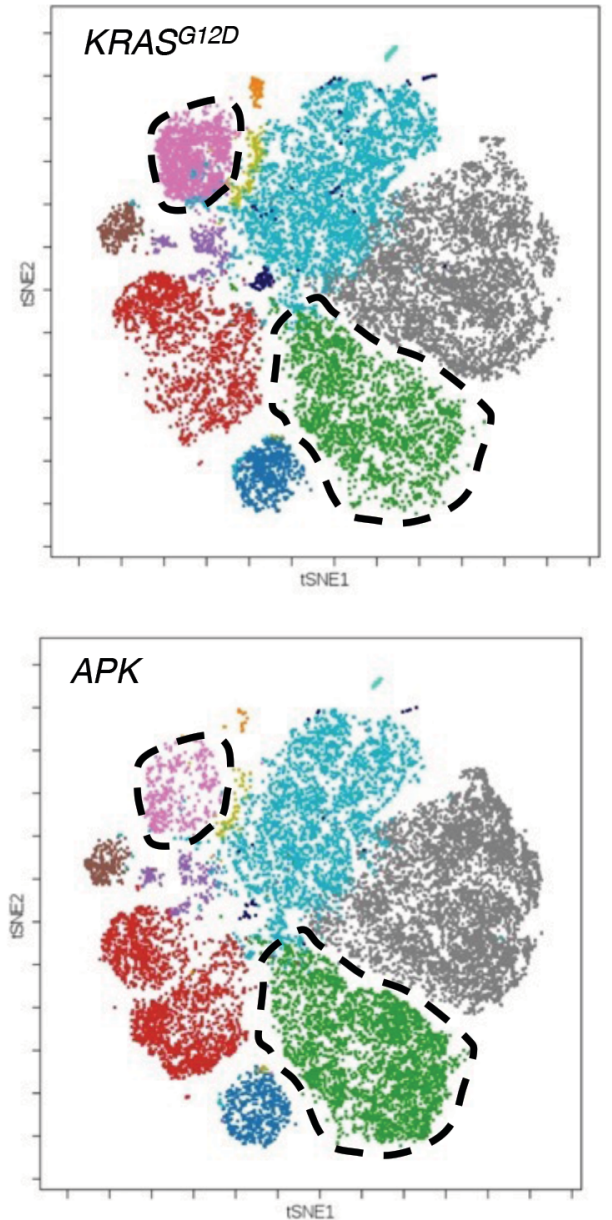

C
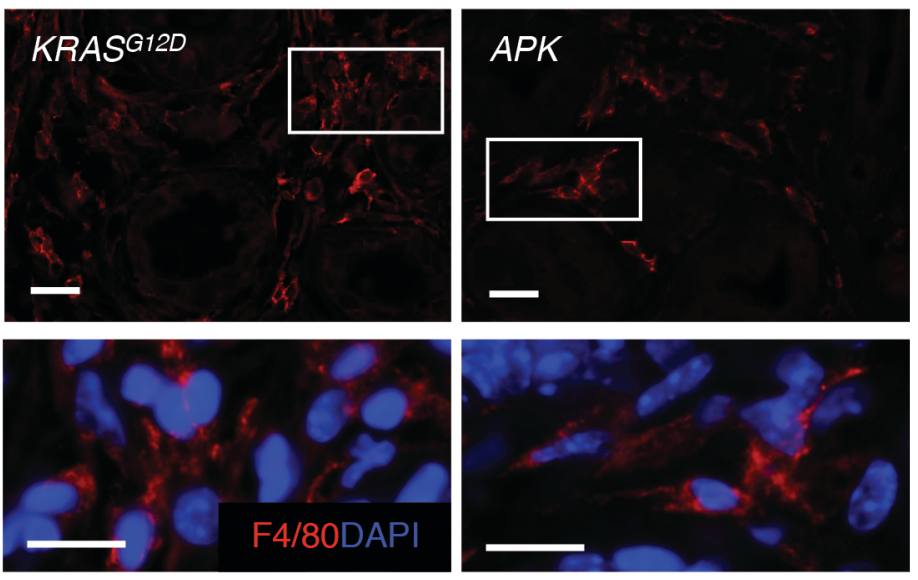

$\mathrm{B}$

MDSCs

TAMs

CD4 Tcells

CD45/CD3

Macrophages (PDL-1+)

TCR $\gamma \Delta$ Tcells

Macrophages

B cells

Dendritic

CD45 Negative

Epithelial

Fibroblast

MDSCs

TAMs

CD4 Tcells

CD45/CD3

Macrophages (PDL-1+)

TCR $\gamma \Delta$ Tcells

Macrophages

B cells

Dendritic

CD45 Negative

Epithelial

Fibroblast
Macrophages

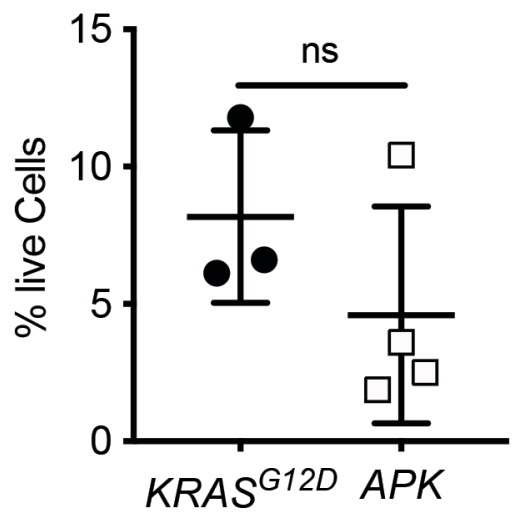

CD4 Tcells

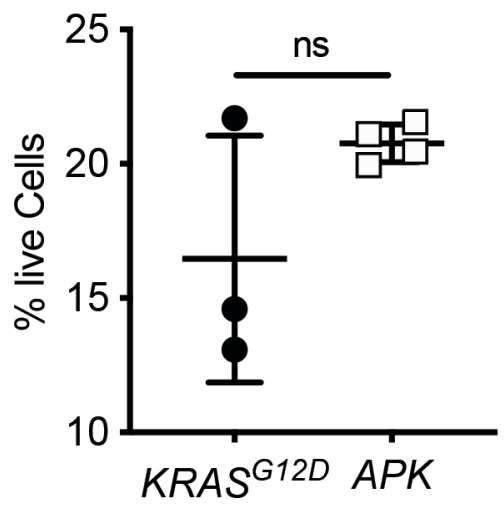

D

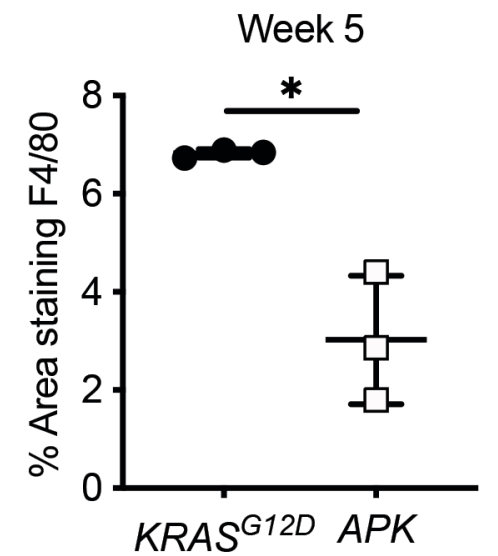

Azizi et al (2019). Figure 8 